Portland State University

PDXScholar

$11-20-1985$

\title{
A Comparative Study of the Developmental Sentence Scoring Normative Data Obtained in Portland, Oregon, and the Midwest, for Children Between the Ages of 5.0 and 5.11 Years
}

Eileen McNutt

Portland State University

Follow this and additional works at: https://pdxscholar.library.pdx.edu/open_access_etds

Part of the Speech Pathology and Audiology Commons Let us know how access to this document benefits you.

\section{Recommended Citation}

McNutt, Eileen, "A Comparative Study of the Developmental Sentence Scoring Normative Data Obtained in Portland, Oregon, and the Midwest, for Children Between the Ages of 5.0 and 5.11 Years" (1985).

Dissertations and Theses. Paper 3547.

https://doi.org/10.15760/etd.5431

This Thesis is brought to you for free and open access. It has been accepted for inclusion in Dissertations and Theses by an authorized administrator of PDXScholar. Please contact us if we can make this document more accessible: pdxscholar@pdx.edu. 
AN ABSTRACT OF THE THESIS OF Eileen McNutt for the Master of Science in Speech Communication with an emphasis in Speech-Language Pathology, presented November 20, 1985 .

Title: A Comparative Study of the Developmental Sentence Scoring Normative Data Obtained In Portland, Oregon, and the Midwest, for Children Between the Ages of 5.0 and 5.11 Years.

APPROVED BY MEMBERS OF THE THESIS COMMITTEE:

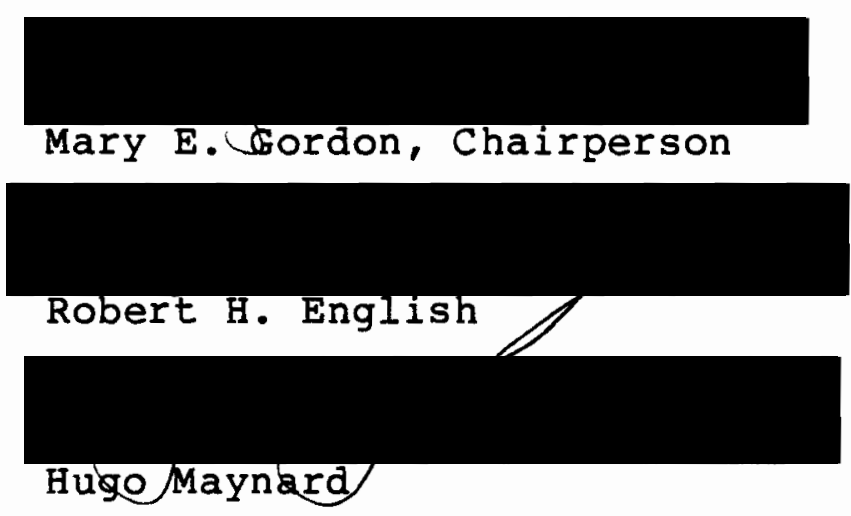

The focus of this study was the Developmental sentence scoring (DSS), developed by Lee and Canter (1971) and Lee (1974). The DSS is used to analyze a corpus of 50 utterances according to eight grammatical categories. Once a DSS score is determined for an individual child, that child's performance can be compared to that of his/ her peers, using the normative data provided by Lee (1974), 
and reported by Koenigsknecht (1974). This normative data has been widely used both clinically, and in research projects with little regard for the validity of the norms when applied outside the Midwest, where it was originally normed.

McCluskey (1984) and Tilden-Browning (1985) replicated Lee's (1974) study with 4 and 6-year old children, respectively. They both found their normative data differed from that established by Lee in the Midwest. Both McCluskey and Tilden-Browning concluded that varying geographical locations may have explained the statistically significant difference in their respective results. The present study sought to continue the investigation into the effect of geographical differences on the DSS scores of children ages 5.0 through 5.11 . The purpose was to replicate Lee's (1974) study in order to determine if significant differences were also evident with a third age group included in Lee's normative population. A collateral purpose was to continue collecting data for Oregon, specifically for the Portland area.

Forty children, chosen on the basis of chronological age, normal receptive vocabulary skills, normal hearing, and a monolingual, middle class socioeconomic background, participated as subjects. A language sample of 50 utterances was elicited from each child and analyzed according to the DSS procedure. DSS means, standard deviations, 
percentiles, range of mean scores, mean weighted developmental score for each grammatical category, and mean number of sentence points were compiled. A two tailed t-test was computed to determine if a difference exists between the means of scores obtained in Portland, Oregon, and the Midwest.

The t-test results indicated that a statistically significant difference between the mean DSS scores obtained in the two different locations did exist, which may be attributed to the geographical difference. A comparison of the two sets of normative data revealed that the mean of the Portland area children was lower than that of the Midwest children. Variables such as the inclusion of subjects from families whose primary wage earner occupational scores spanned the middle class continuum, the receptive vocabulary skills of the subjects, and the type of stimulus materials used do not appear to have significantly influenced the reported differences. Other variables may have had some affect on the results. The number of children in preschool or the demographics of the given area may have differed from Lee's (1974) study. Differences in corpus selection, i.e., utterances obtained while playing with toys or utterances obtained during the re-telling of the "Three Bears," may be a possible explanation for the differences in the two studies. Very similar variances from Lee's (1974) study were 
found by McCluskey (1984) and Tilden-Browning (1985) in their respective Oregon studies. Since geographic location was the only systematically manipulated variable, it is feasible that differences in DSS scores between the Midwest and Oregon may be attributable to the difference in geographic location. It would appear tht further research is necessary before the original DSS normative data can be used without reservation outside of the Midwest. 
A COMPARATIVE STUDY OF THE DEVELOPMENTAL SENTENCE SCORING NORMATIVE DATA OBTAINED IN PORTLAND, OREGON, AND THE MIDWEST, FOR CHILDREN BETWEEN THE AGES OF

5.0 AND 5.11 YEARS

by

EILEEN MCNUTT

A thesis submitted in partial fulfillment of the requirements for the degree of

MASTER OF SCIENCE IN SPEECH COMMUNICATION:

with an emphasis in

SPEECH-LANGUAGE PATHOLOGY

Portland State University

1985 
TO THE OFFICE OF GRADUATE STUDIES AND RESEARCH:

The members of the Committee approve the thesis of Eileen McNutt presented November 20, 1985.

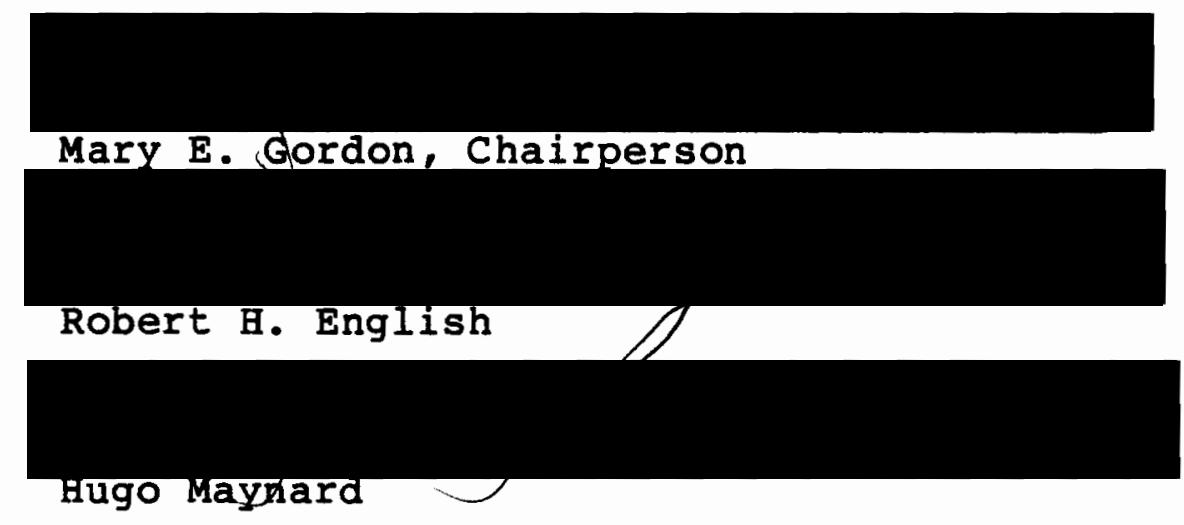

APPROVED :

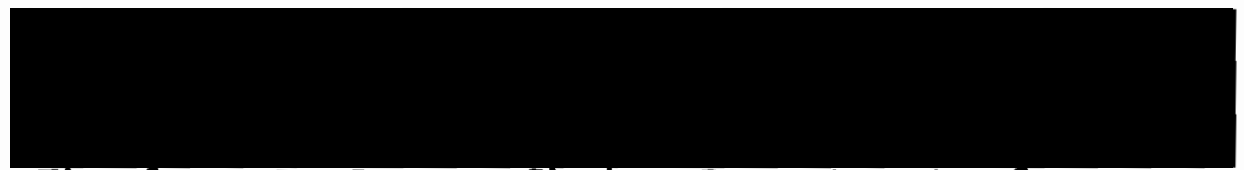

Theodore G. Grove, Chair, Department of Speech Communication

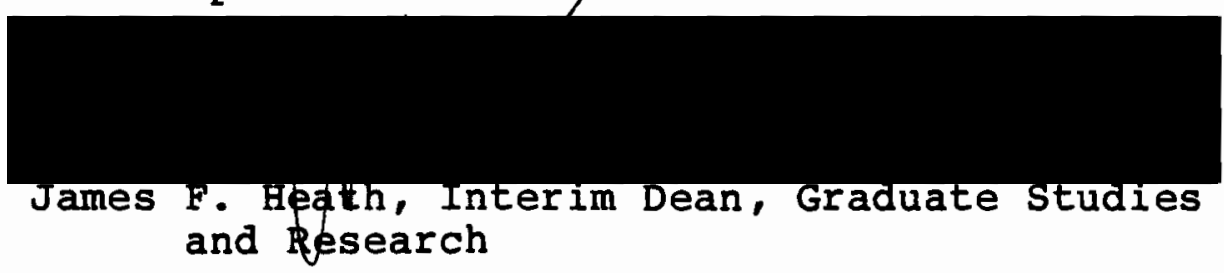




\section{DEDICATION}

This thesis is dedicated to my husband, Tim Keeley, in appreciation of his continual humor and encouragement, and more importantly, in appreciation of his commitment to helping those who need it most. 


\section{ACRNOWLEDGEMENTS}

I wish to thank my family for their support during my graduate program. They always seemed to know just when to phone with words of inspiration or to offer a patient ear. I want to thank my parents for teaching me the value of education, and my sister for modeling what it is to be an outstanding educator.

All the school personnel involved in my study deserve a big hug! I want to thank the administrators, Jack Drumm from Jennings Lodge Elementary, Jim Gunis from Gaffney Lane, and Les Larson from Oak Grove Learning Tree, for their approval and support. My thanks are due to the classroom teachers, Erin Prince, Nancy Combs, Linda Cella, and Jane Collier, who cheerfully endured many interruptions of their instruction. I also want to thank the secretaries, Louise Holladay, Donna Robinson, and Charlene Jensen, who fielded phone calls and kept me organized. Conducting this study was a pleasure. I was able to meet many interesting parents, and I wish to thank them for allowing me to "borrow" their children for an hour. The children were wonderful. Their charming conversations and delightful stories kept me going through some difficult moments.

I want to thank Mary Gordon for accepting the role of of thesis advisor for a student whom she hardly knew. I 
have enjoyed our contact, and I appreciate her perseverence through all the long distance phone calls and correspondence. I wish to thank Dr. Robert English for his gift of caring, and for his persistent nudging, which has resulted in the completion of this thesis. I want to express my appreciation for the late Shari Kazdoy, who is largely responsible for making possible my completion of the required course work in one year's time. Her willingness to take up the cause of an individual student will always be remembered.

I owe sincere thanks to Kathy McCluskey who originated this thesis topic, and to stacy Tilden-Browning who completed the second study. Their willingness to share notes, materials, and empathy is much appreciated. I want to especially thank stacy for guiding me through the maze of statistics!

I want to thank all the graduate students who made my PSU experience so memorable. It was a unique group; I miss the individuals, and the comraderie that developed that year. I also wish to thank my colleagues Lori Hickman and Karen Lacey for sharing their notes and books, used during their study at PSU.

Finally, silly as it may seem, I want to remember our late cat, sly, who kept me warm and comforted during many a late night of typing. 
TABLE OF CONTENTS

Page

DEDICATION

ii i

ACKNOWLEDGEMENTS . . . . . . . . . . . . . iv

LIST OF TABLES . . . . . . . . . . . . . . viii

CHAPTER

I INTRODUCTION AND STATEMENT OF PURPOSE • • • • • 1

Introduction . . . . . . . . . . . 1

Statement of Purpose... . . . . . . . 3

II REVIEW OF THE LITERATURE . . . . . . . . . 5

Types of Oral Language Sampling . . . . 5 Word Counting Methods

Measures of Structural Complexity

Variables Effecting Oral Language Sampling 7 Subject Selection

Elicitation

Transcription Methods

Segmentation Procedures

Use of Normative Data . . . . . . . 13

Developmental Sentence Scoring . . . . . 14

Studies Using DSS ............ 16

The Need for Establishing Local DSS Norms 18

III METHODS AND PROCEDURES . . . . . . . . . 20

Subjects ............... 20

Instrumentation ............ 21

Screening . . . . . . . . . . . . . 22

Language Sample Collection . . . . . . 23

Transcription .............. 24

Scoring . . . . . . . . . . . . 25

Examiner Reliability... . . . . . 25

Data Analysis . . . . . . . . . . 26

IV RESULTS AND DISCUSSION • . • . . • . • . . . 28

Results ............... 28

Discussion ............. 38 
TABLE OF CONTENTS (Continued)

Page

$\mathrm{V}$ SUMMARY AND IMPLICATIONS ......... . 52

Summary . . . . . . . . . . 52

Implications . . . . . . . . . . 55

SELECTED BIBLIOGRAPHY . . . . . . . . . . . 58

APPENDIXES . . . . . . . . . . . . . . 64 
IIST OF TABLES

TABLE

Page

I DSS Means And Standard Deviations For Forty Subjects By Three-Month Age Groups (Portland, Oregon) . . . . .

II Range And Percentiles of DSS Scores For Forty Subjects By Three-Month Age Groups . . . . . . . . . . . 30

III Mean Weighted Developmental Scores For The DSS Component Grammatical Categories And Mean Number of Sentence Points For Forty Subjects . . . . . . . . .

IV Combined Mean Developmental Scores Per Component Grammatical Category Based On 50-Utterance Samples For Forty Subjects

V A Comparison of The DSS Means And Standard Deviations Obtained In The Midwest And Portland For 5-Year Olds........

VI A Comparison of The Ranges And Percentiles OF DSS Scores For The Midwest And Portland, Oregon For Children 5.0 Through 5.11 Years . . . . . . . . . .

VII A Comparison of The Number of subjects Per Percentile Level Using Midwest Norms And Portland, Oregon Norms . . . . . 35

VIII A Comparison of The Mean Weighted Developmental Scores on The DSS Component Grammatical Categories And The Mean Number of Sentence Points For Forty Subjects By Geographical Location. . .

IX A Comparison of The Mean Developmental Scores Per DSS Component Grammatical Category By Geographical Location

X A Comparison of Mean Length of Response Scores Obtained From Fifteen Utterances Elicited with Toys And Re-Telling The "Three Bears" For 10 Subjects Age 5.6 To 5.8 Years .............. 
TABLE

XI A Comparison of Mean DSS Scores And PPVT-R

Performance For Each Three-Month Age Sub-

Group ................... . 48

XII A Comparison Of The DSS Component Grammatical

Category Scores In The Midwest And Portland, Oregon

XIII A Comparison of The Mean DSS Scores Obtained In The Midwest With Those Obtained In

Oregon .. . . . . . . . . . . 50 
CHAPTER I

INTRODUCTION AND STATEMENT OF PURPOSE

\section{Introduction}

Research in the field of communication disorders has broadened in the last thirty years to include the semantic and syntactic components of language. Emphasis has shifted away from the phonological aspect of language development, and psycholinguistic studies have provided new insight into the language development of children. Many researchers have analyzed spontaneous language samples of children using Chomsky's (1957, 1965) transformational grammar and Brown's (1973) case grammar. Studies also have included the development of single categories of syntactic and morphologic forms, such as Cazden's (1968) study of noun and verb inflections, Brown's (1968) report on the development of Wh-questions, and Klima and Bellugi's (1966) study of negatives. These studies have provided the groundwork in the relatively new investigative field of expressive language development. Methods of sentence structure analysis have varied, but the basic assumption has been constant; words which occupy the same position in a string are assumed to form a 
grammatical class. These grammatical classes are developmental in nature and are subject to the rules of a child's developing grammar (MCNeil, 1970). Studies have established that syntactic structure development follows certain general principles and proceeds in fairly uniform steps (Lee, 1974).

The developmental nature of child language became generally accepted, but the variations in study methods have made cross-study comparisons difficult. A standard system was needed to compare the developing rules of different children and to measure the syntactical growth of an individual child. In 1971, Lee and Canter provided such a system, i.e., Developmental Sentence Scoring (DSS). The DSS is a tool for the systematic assessment of children's spontaneous language samples. A scoring system was developed in which numerical values were assigned to specific grammatical structures. Normative data were then collected from 160 children in 1971 and from an additional 40 children in 1974, throughout three Midwestern states. These data determined the varying grammatical complexities of children's language through the stages between ages 2 years and 7 years. Using this tool, a clinician may make a detailed and quantified evaluation of a client's use of grammatical rules and compare the client's usage to that of his/her peers.

The DSS has become a widely accepted clinical tool 
throughout the United States, and has been used as a tool in further research projects. Caution needs to be exercised when applying normative data to persons outside the geographical area in which the data were originally obtained. Lyman (1965) suggests that normative data may be invalid when applied outside the area where the information was obtained. McCluskey (1984) and TildenBrowning (1985) studied 4-year old and 6-year old children, respectively, and found significant differences in DSS performance when comparing the scores of children in the Portland, Oregon, area with those of the children involved in the original study in the Midwest. Mccluskey and Tilden-Browning both concluded that clinicians may need to be wary of strictly applying the DSS norms, depending on their geographical location, and that clinicians may need to develop local normative data to assure valid assessments.

\section{Statement of Purpose}

The purposes of this study were to replicate the research of Lee and Canter (1971) and Lee (1974), comparing the DSS normative data (Roenigsknecht, 1974) with the data obtained in Portland, Oregon, for children ages 5.0 to 5.11 years old, and to provide developmental norms for 5-year old children for the geographical area of Portland, Oregon, using the DSS procedure. This is the third study in the Portland, Oregon, area, following 
McCluskey (1984) and Tilden-Browning (1985), to replicate the original DSS studies, and to provide normative data for the Portland, Oregon, area.

The two research questions this investigation sought to answer were:

1. What are the descriptive statistics of the DSS on language samples obtained on 5.0 to 5.11 year old children in Portland, Oregon, represented by:

a. the DSS mean and standard deviation of the overall DSS score;

b. the range and percentiles of the average DSS sentence score;

c. the mean weighted scores for each of the DSS component grammatical categories; and

d. the mean number of DSS utterances earning a sentence point for grammatical completeness?

2. Is there a significant difference in the mean DSS score obtained in the Midwest (Roenigsknect, 1974; Lee, 1974) and that obtained in Portland, Oregon? 
REVIEW OF THE LITERATURE

The analysis of spoken language has long been a fundamental research and clinical tool in the study of child language. Researchers have continually endeavored to refine their tools in order to isolate behaviors that might predict a child's language maturity in general (Barrie-Blackley, Musselwhite, and Rogister, 1978). This review of the literature presents a historical perspective regarding the types of expressive language analysis used and the variables which may affect individual performance and the comparison of group performances. The DSS, being the focus of this study, will be described relative to those variables and the normative data provided by Lee (1974) and Roenigsknect (1974) will be presented. Nationwide studies utilizing the DSS will be reviewed and the importance of developing local norms will be established.

\section{Types of Oral Language Sampling}

Word Counting Methods

Nice (1925) first suggested that a child's stage of language development could be determined by averaging the length of the child's sentences. McCarthy (1930) elicited 
50 consecutive, verbatim responses from children using picture books and toys. She then averaged the number of words per response, providing a mean length of response score (MLR). McCarthy (1954) developed rules for distinguishing words into meaningful units, yielding a mean length of utterance (MLU). MLU was later refined by Winitz (1959). Number of Words (Hass and Wepman, 1973; Jones and McMillan, 1973; Longhurst and Grubb, 1974), Total Number of One Word Responses (Lovell, Hoyle, Sidall, 1968; Minifie, Darley and Sherman, 1963), and Mean Number of Words in Five Longest Responses (Minifie et al., 1963) are all methods of word counting used to determine levels of language development.

\section{Measures of Structural Complexity}

As the importance of psycholinguistics became established, the use of word counting methods declined and researchers shifted toward more structural analyses to determine language levels (Ervin and Miller, 1963). Mean Length of Utterance in Morphemes (MLU-M) emphasizes linguistic complexity more than MLR in words, providing a more sensitive instrument (Barrie-Blackley et al., 1978; Brown, 1973; Lovell et al., 1968). The Structural Complexity Score (SCS) (MCCarthy, 1930) was an early attempt to measure grammatical content. Utterances were designated as complete or incomplete responses and classified by sentence types. Miner (1969) developed a numerical 
weighting system for concurrent analysis of sentence length and complexity called Length of Complexity Index (LCI). Noun phrases, verb phrases, questions, and negative forms are assigned corresponding points; the sum of these points, divided by the total number of sentences yields a LCI score. The Developmental Sentence Scoring (DSS) (Lee, 1974 and Lee and Canter, 1971) also employs a numerical weighting system. The weighted values are assigned to structures according to their developmental level. Fifty, complete, different, consecutive, non-echoic sentences are scored individually with respect to their content of eight grammatical classes: main verbs, secondary verbs, negatives, conjunctions, interrogative reversals, and wh-questions. An additional point is awarded if the sentence is grammatically and syntactically correct in accordance with standard adult English. All points are summed and divided by 50 (the number of responses) to yield a DSS score.

\section{Variables Effecting Oral Language Sampling}

Musselwhite (1975) concludes:

it appears that there are nearly as many ways of eliciting, transcribing and analyzing the samples as there are papers on oral language sampling.

Review of the oral language sampling literature reveals the need for more systematic procedures and for more control over the many variables inherent in oral language sampling. Variables to be reviewed here are subject 
selection, elicitation, transcription, and segmentation procedures.

Subject selection

Some studies have demonstrated differences in language performance when comparing varying populations. Bernstein (1961) found that lower socioeconomic status subjects produced more restricted language usage; whereas middle socioeconomic status subjects produced more elaborated language. Labov (1970) contended that this difference was the result of the defensive posture the lower SES children may have experienced due to the unfamiliar and threatening testing situations. Jones and McMillan (1973) performed an oral language study in three envivironments to determine the effects of situational factors presented by Labov (1970). They found that the situational factors effected both the low and middle SES groups and that the lower SES subjects were generally less fluent and used fewer grammatical complexities than their middle SES counterparts. Performance differences between males and females have also been noted. Watson (1976) found that 4-year old male subjects produced more sophisticated language than 4-year old females as measured by MLU. In contrast, in 1974, Johnson examined language performance of varying social classes, races, and the sexes and found no significant differences when performance IQ was a controlled factor. 
Elicitation

Another variable observed in the literature is that of subject-examiner interaction. Early studies (McCarthy, 1930; Templin, 1957) utilized the traditional model of an adult examiner. Jones and McMillan (1973) compared results using the traditional model with language sample results elicited by a peer interviewer and found no overall differences. Shatz and Gelman (1973) studied the interaction of 4-year old subjects with older and younger children. They found the subjects controlled their language and decreased their language level when speaking with younger children, and understandably did not shift their language usage up above their functional level when speaking with older children and adults. Longhurst and Grubb (1974) sampled the language of educably mentally retarded and trainably mentally retarded children, comparing examiner-client and client-peer interactions. The total number of words used was higher in the examiner-client exchange, but more complex language was used when no adult was present. Smith (1970) found significantly more speech was produced by subjects when evaluated within a group of four children than was produced when a subject was evaluated individually by an examiner. Examiner familairity was studied by Fuchs, Fuchs, Garwick, and Featherstone (1983). They compared language test performance of language handicapped preschoolers when examined by familiar classroom teachers and an 
examiner who was a stranger to the children. Subject performance was significantly better with familiar examiners, particularly on highly symbolic tasks.

Physical settings (e.g., home, clinic, playroom) are variables that have also been considered as to their effect upon the language sampling process (Johnson, 1974; Longhurst \& Grubb, 1974; Mueller, 1972). When reviewing these studies, it is difficult to determine the isolated effect of environment due to failure to control for other variables. Longhurst and Grubb (1974) studied clients in both the waiting room and the clinic room and found differences in performance; however, variables such as subject-examiner interaction and spontaneous conversation versus the interview method of sampling were not considered nor controlled.

Various stimuli have been used to elicit oral language samples. Ahmend (1973) compared the use of picture cards featuring one object with picture cards featuring multiple objects, when sampling the language of educably and trainably mentally retarded subjects. The multiobject picture cards yielded significantly larger LCI and MLR scores with both groups. Toys, still pictures, and movies were presented to three groups of mentally retarded youngsters by Mintun (1968). The toy stimuli elicited a greater variety of words and higher MLR scores although LCI scores were higher in response to the film medium. 
Cowan, Weber, Hoddinott and Klein (1967) compared MLR in response to ten different pictures. One picture consistently elicited the smallest MLR with all subjects, and conversely, another picture consistently elicited the highest MLR scores. The authors and two psychology interns were unable to develop a rationale for this result.

The type of instructions and modelling strategies used by examiners appears to be the least standaradized aspect of oral language elicitation; many authors have commented on this oversight and have recognized the need for further research (Cowan et al., 1967; Jones and McMillan, 1973; Longhurst and Grubb, 1974). One recent study did attempt to address this concern. Stalnaker and Creaghead (1982) examined three different modes: 1) retelling a story with toys; 2 ) playing freely with toys; and 3) answering questions with toys. Retelling a story with toys yielded the largest MLU, and questions with toys elicited the most total number of words. They concluded that questioning does not inhibit a child and that story retelling can be useful in eliciting the most sophisticated language performance.

\section{Transcription Methods}

Transcription procedures are important variables with implications for reliability of oral language measures. Betts (1934) discovered that only 32 percent of 
the subjects' utterances were recorded when using longhand transcription. Siegel (1962) concluded that longhand recording results in reduced accuracy of the transcription. Winitz (1959) found greater agreement between examiners' transcriptions when using tape recordings of oral language samples. Siegel (1962) found the training of typists to be an important factor for increased accuracy in sample transcription. Barrie-Blackley et al. (1978) also found training of the transcribers to be influential, as well as contextual factors, intelligibility, complexity and response length. Siegel (1962) also recognized contextual, factors to be critical, specifically when transcribing samples from very young children. Recording examiner remarks and questions was found to improve the ease and accuracy of transcription.

\section{Segmentation Procedures}

Once a language sample has been transcribed, the next variable to consider is its segmentation. Investigators have used various sets of rules to segment language samples into units for analysis. McCarthy (1930) isolated an utterance if it was marked off from the preceding and succeeding remarks by pauses. Templin (1957) determined the length of responses by the natural breaks in the child's verbalization, rather than on the basis of adult sentence types. Siegel (1962) distinguished units as being marked on either side by pauses or changes in 
inflection. Lee (1974) uses intonational cues to separate utterances and provides five guidelines for segmenting compound sentences (Appendix A).

\section{Conclusion of the Effects of Variables}

Failure to control variables has made comparisons among studies difficult (Cowan et al., 1967) and Leonard (1972) cautions that the lack of uniform and carefully controlled procedures might result in invalid conclusions or misinterpretations. Clinicians must be aware of the variables involved in eliciting and analyzing oral language, so that variables can be systematically controlled in order to derive representative and meaningful results.

\section{The Use of Normative Data}

McLoughlin and Lewis (1981) assert that the characteristics of a normative sample must reflect the characteristics of the individual student who is tested; otherwise, the interpretation of obtained scores is difficult and perhaps misleading. In order for norms to be used to the best effect, examiners must determine that the normative sample is representative of local students in terms of such characteristics as age, sex, race, socioeconomic level, native language, general experience, and geographic area (Hammill and Newcomer, 1982). As reviewed above, the procedures and analysis techniques under which an instrument is standardized, are also variables to consider when 
applying normative data (Leonard, 1972). Since the DSS is the focus of this current study, a description of the sample, procedures and geographic area used to develop its normative data will be presented.

\section{Developmental sentence scoring}

The initial DSS study represented the work of Lee and Canter (1971). The DSS was administered to 160 children between the ages of 3.0 to 6.11 years who were not clients at the Northwestern University Speech Clinic in Chicago, Illinois. Five males and five females were selected to represent each three month age interval, in order to obtain an equal distribution of age and sex. The children were from monolingual homes where standard English was spoken. All but two of the subjects were from middle income families as measured by the Warner Scale (Warner, Meeker and Ellis, 1949). The Peabody Picture Vocabulary Test (Dunn, 1965) was administered and the study included subjects obtaining IQ scores that fell within the 85 to 115 range.

Lee (1974) later expanded the sample to include 40 additional children between the ages of 2.0 and 2.11 years, increasing the total number of subjects to 200 . These children resided in Illinois, Michigan and Maryland; all but three met the requirements of the original study. Two of those exceptions were children whose family income 
fell slightly below the middle group and the other exception was a child whose family was not "classifiable" as measured by the Warner Scale. All subjects were judged to be free from hearing sensitivity deficits or poor speech intelligibility. No children with extraordinary developmental or social histories were included in the study. Examiners were speech-language pathologists at the Master's degree level. The examiners first presented three groups of toys and prompted the children to talk about them as they played with them. Pictures from We Read Pictures, We Read More Pictures and Before We Read (Robinson, Monroe and Artley, $1962 \mathrm{a}, \mathrm{b}, \mathrm{c}$ ) were then presented. Finally, the children were encouraged to retell the story of the "The Three Bears" using pictures from What's Its Name? (Utley, 1950). The examiners attempted to elicit the subjects' most sophisticated syntactical and morphological structures by questioning and modelling high level structures. The length of the recording sessions ranged from 15 to 30 minutes and elicitation procedures were kept as systematic as possible. All responses were tape recorded and the last 50 sentences of each sample were scored and analyzed.

Descriptive statistics were applied to the data collected. The score distributions were plotted on normal curves for each age group and percentile values were calculated from the normal distribution curve for the 90 th, 
75 th, 50 th, 25 th and 10 th percentiles.

\section{Studies Using Developmental Sentence Scoring}

The DSS has been the subject of numerous research projects (Barrie-Blackley et al., 1978). These studies have been pursued in a variety of settings, with the apparent assumption that the DSS norms may be generalized when used with varying populations.

Longhurst and Shrandt (1973) compared the DSS with the Linguistic Analysis of Speech Samples (LASS) and the Indiana Scale of Clausal Development (ISCD) in a Midwestern study; they found the DSS to be the easiest to use, yielding the lowest language scores of the three measures. When developing the Carrow Elicited Language Inventory (CELI) in Texas, Carrow (1974a) used the DSS normative data as the comparison standard for normal language development. Carrow (1974b) found that the DSS and the CELI both identified subjects exhibiting language delays with a correlation of .79. Carrow interpreted this high correlation as evidencing strong construct validity of her instrument.

Longhurst and File (1977) used the DSS when comparing sampling stimulus methods in Manhattan, Kansas. Single object pictures, toys, multi-object pictures and adult-child interview were the techniques used. Longhurst and File determined that the adult-child conversation 
yielded the highest DSS scores, but concluded that standardization of elicitation techniques is difficult due to personality differences of individual subjects. The DSS and CELI were used in St. Louis, Missouri, by Geers and Moog (1978) to compare the spontaneous language of hearing impaired children with normally hearing children. They found that the two groups differed in the manner in which similar overall DSS scores were obtained; categorical analysis evidenced a difference in performance profiles. Kramer, James and Saxman (1979), in Syracuse, New York, compared language samples obtained in clinical settings by speech-language pathlogists with those obtained at home by mothers of five year old subjects. Differences were found on MLU measures, but not on the DSS, indicating that the subjects produced longer utterances in their own homes; however, the syntactic complexity of their utterances was similar in both settings. Valenciano (1981) in Portland, Oregon, compared the DSS scores derived from analyzing 25-, 50- and 75- utterance language samples. No significant score differences were obtained between the various sample sizes.

Blaxley, Clinker and Warr-Leeper (1983) used the DSS to examine the comparative efficiency of the Bankson Language Screening Test and the Fluharty Preschool Speech and Language Test as screening tools. They defined students performing below the loth percentile on the DSS as 
language impaired and found that the Bankson Language Screening Test was the most successful in identifying children with language impairments.

The Need for Establishing Local DSS Norms

The DSS has been widely distributed and used throughout the United States. As reviewed in the literature, it has been employed clinically to determine degrees of language delay and has also been implemented investigatively as a criterion for establishing that subjects exhibit normal language skills. Attention has not focused on the validity of this DSS usage when applying the normative data in geographical locations outside of the area in which the original studies were performed.

The possibility of varying performance in different geographical settings has been considered with other language assessment tools. Lyman (1965) concluded that caution needs to be exercised when applying the norms of the PPVT outside of Nashville, Tennessee. Butler (1972) indicated that the use of the Verbal Language Developmental scale in large urban areas may be inappropriate because it had been normed on "normal speaking white children of Central Utah." Cazden (1978) noted that although the CELI manual clearly states that the normative sample was comprised of only white, middle class children 
from an urban community, no mention has been made of the questionable validity of the global application of those norms.

Elliott and Bretzing (1980) recommend the development of local norms to be used for comparative purposes with the national norms, or to be used to complement national norms. McCluskey (1984) and Tilden-Browning (1985) compared the DSS scores of 4-year old and 6-year old children, respectively, who were tested in the Portland, Oregon area with those of the children in the original normative study. Statistically significant differences were found between the mean scores, with the subjects in Oregon scoring lower than the original normative data. In order to implement the DSS most effectively, it would appear that local normative data need to be collected in the specific geographical region of its use. 
CHAPTER III

METHODS AND PROCEDURES

$\underline{\text { Subjects }}$

Subjects were selected from Gaffney Lane Elementary School, Oregon City; Jennings Lodge Elementary School, Milwaukie; and Oakgrove Learning Tree, Milwaukie, all located in suburbs of Portland, Oregon. Included in this study were 40 normally-developing children, ages 5.0 through 5.11 years, with five boys and five girls in each three-month interval (5.0 through $5.2,5.3$ through 5.5, 5.6 through 5.8 , and 5.9 through 5.11 ).

After selection for the subject pool based on age, subjects were required to meet the following criteria:

1) white, living in monolingual homes where standard English of general American dialect is spoken;

2) from middle-class families as represented by education and occupational status according to the U.S. Bureau of Census (1963);

3) normal hearing sensitivity as defined by audiometric screening at $20 \mathrm{~dB}$ unilaterally;

4) no demonstrated or suspected physical, or social delays as observed by the investigator and the classroom teacher; and

5 ) normal receptive vocabulary as demonstrated by an age-appropriate score (within one standard deviation above/below mean for age) on the Peabody Picture Vocabulary Test-Revised, Form I (Dunn, 1979).

The three building administrators included a notice 
in the parent newsletters describing the study and encouraging parents to allow their children to participate. Parent permission letters were sent to the parents of potential candidates (Appendix B). Those children with returned, signed permission forms were then included in the screening process.

\section{Instrumentation}

A portable Maico Ma-20 audiometer ANSI 1968 was used to administer the hearing screening tests to the subjects. A Bell and Howell tape-recorder, Model 3081B, with an Electrovoice Professional Dynamic microphone attached, was utilized to record the children's language samples.

The Peabody Picture Vocabulary Test-Revised, Form L (Dunn, 1979) was used to determine the subjects' receptive vocabulary age equivalents, in order to establish that the subjects exhibited normal receptive language development. Lee and Canter (1971) and Lee(1974) administered the original Peabody Picture Vocabulary Test, Forms A and B (Dunn, 1965) in their studies. Mccluskey (1984) compared performances on forms $A$ and $B$ with the revised Form $L$ and found no significant differences between the original and revised studies.

The DSS (Lee, 1974) is designed to analyze the spontaneous utterances of children between 2.0 and 6.11 years of age. Utterances are tape recorded, transcribed and 
analyzed by the administering clinician. Fifty intelligible, complete, consecutive, non-echoic, different sentences are chosen from the sample for analysis. Sentences are defined as those utterances which contain a noun and a verb in subject-predicate relationship. Weighted scores are assigned to structures divided into eight categories: indefinite pronouns and/or modifiers, main verbs, personal pronouns, secondary verbs, negatives, conjunctions, interrogative reversals, and Wh-questions (Appendix C). Specific structures are grouped according to general developmental order within each category. Later-developing structures are assigned increasingly higher numerical values such that the earliest developing words and structures are assigned one point and higher values are assigned to the more complex structures, with the highest score being eight points. Review of the literature and observations by Lee determined the accepted developmental ages for each structure (Lee, 1974). The category scores are added for each utterance; a sentence point is then added to the utterance score for those responses which are accurate in all respects, i.e., syntactically and semantically (Lee and Canter, 1971).

Screening

Screening procedures took place in the speech-language rooms in the respective elementary schools and in a 
quiet room made available for this purpose in the day care center. Upon receiving written parental consent for subject participation, this investigator administered an audiometric screening and Form $L$ of the Peabody Picture Vocabulary Test-Revised. Classroom teacher report and investigator observation provided information regarding any exceptional physical, social, and/or conduct behaviors. Forty boys and girls who met the specified screening criteria were included in this investigation.

\section{Language Sample Collection}

This investigator met with each child, individually, for approximately 45 mintues and elicited spontaneous language samples within the confines of the speech-language rooms. Those children producing complete sentences in at least 50 percent of their utterances were used as subjects.

A tape recorder was positioned within two feet of the children. The children were seated at a padded table or on the carpeted floor, in whichever position best facilitated their willingness to talk and interact.

The children were first presented with a doll family and plastic furniture, a transport truck with small cars, and a small barn with farm animals in it, in order to encourage spontaneous speech. Descriptions were elicited by presenting picture cards from the Game oriented 
Activities for Learning-GOAL (Karnes, 1972). The picture book of the Three Bears (Utley, 1950) was used in story retelling tasks. Materials were presented in this order to all children to provide uniformity from one sampling session to the next.

This investigator attempted to avoid being corrective, using instead parallel talk and open-ended questions to stimulate expressive language responses of more than single utterances. A variety of grammatical structures was used by the examiner as appropriate, to encourage the child's maximum performance. To ease the task of tape transcriptions, many of the children's utterances were repeated during testing by the examinez in order to eliminate potential confusions caused by pronunciation inaccuracies or ambient noise.

\section{Transcription}

Methods of transcription, recommended by Lee (1974) were used to transcribe the utterances of each child (Appendix D). Lee's (1974) guidelines were then applied for separating and combining sentences (Appendix A).

The corpus sample included 50 complete, consecutive, different, intelligible, non-echoic sentences. Sentences were considered complete if they contained a noun and verb in subject-predicate relationship; sentences were not required to be accurate in all grammatical aspects. The 
selected sentences were then hand recorded onto a DSS score sheet.

\section{Scoring}

This investigator was the collector, transcriber and analyzer of all the language samples. The examiner has thorough familiarity with Lee's text, Developmental Sentence Analysis (1974), and had used the DSS clinically while serving three years as a Speech-Language Pathologist in the public schools.

All scoring rules established by Lee (1974) and used in the original study were strictly followed (Appendix E). Individual grammatical structures, analyzed in the corpus were assigned developmentally weighted numerical values according to category. The category scores were then summed for each utterance and an additional point was added if the utterance was accurate and complete in all aspects (semantically, syntactically, morphologically). Those structures that were inaccurate were indicated with an attempt mark (-), in place of a numerical score. After each response was scored, the 50 individual response scores were added and then divided by 50 to derive the DSS score.

\section{Examiner Reliability}

Interjudge reliability was obtained between the investigator and a Speech-Language Pathologist holding 
the Certificate of Clinical Competence granted by the American Speech and Hearing Association. A 50-utterance language sample was presented to the judges for independent DSS analysis. Interjudge reliability was 96 percent. Postanalysis calibration between judges was conducted to provide guidelines under which the remainder of the language samples were analyzed.

One week after the interjudge comparison, 25 utterances were selected from the original 50-utterance sample. These utteranes were re-scored by the investigator, resulting in an intra-judge reliability of 96 percent.

\section{Data Analysis}

DSS scores were computed for each child's language sample. Descriptive statistics were then applied to determine mean DSS scores, percentile values, mean weighted developmental scores for each component grammatical category, and the mean number of DSS utterances earning sentence points. The descriptive statistics obtained in the Portland, Oregon area were then compared to those obtained in the Midwestern study by Lee (1974) and reported by Koenigsknecht (1974). To establish if a statistically significant difference existed between the overall mean DSS score for the oregon sample and that for the Midwest sample, a two-tailed t-test for independent means was computed according to the procedures described 
by Bruning and Kintz (1977) for determining the difference between a sample mean and a population mean. 


\author{
CHAPTER IV \\ RESULTS AND DISCUSSION
}

\title{
Results
}

This study sought to compare DSS descriptive statistics for children ages 5.0 through 5.11 reported by Lee (1974) and Koenigsknecht (1974) with those gathered in Portland, Oregon. Language samples were elicited individually from forty, 5-year old children. All the children met the criteria described by Lee in her 1974 study. The DSS procedures established by Lee were applied to the language samples and DSS descriptive statistics were developed for the geographical area of Portland, Oregon. The descriptive statistics for Portland, Oregon, were then compared with Lee's (1974) Midwest DSS normative data, in order to determine if geographical differences affected the DSS performance of children ages 5.0 through 5.11 . The data compiled for the current study addresses the research questions.

The first research question was: What are the descriptive statistics of the DSS on language samples obtained in Portland, Oregon for children ages 5.0 through 5.11? Table I presents the mean and standard deviation 
for the total group and for each of four, 3-month age groups. The subgroup means ranged from 7.42 to 8.70 , with a total group mean of 7.61 and a standard deviation of 1.25 .

\section{TABLE I}

DSS MEANS AND STANDARD DEVIATIONS FOR FORTY SUBJECTS BY THREE MONTH AGE GROUPS (PORTLAND, OREGON)

\begin{tabular}{cccc}
\hline Age Groups & $\mathrm{N}$ & Mean DSS & SD \\
\hline $5.0-5.2$ & 10 & 7.42 & 1.13 \\
$5.3-5.5$ & 10 & 6.33 & 1.07 \\
$5.6-5.8$ & 10 & 8.00 & .92 \\
$5.9-5.11$ & 10 & 8.70 & 1.25 \\
$5.0-5.11$ & 40 & 7.61 & \\
\hline
\end{tabular}

Table II shows the ranges and percentiles of the DSS scores for the total group and for each of the three-month age subgroups. The total group range was 4.41 to 9.62 , with the $10 t h, 25 t h, 50 t h, 75 t h$ and 90 th percentile values being $5.74,6.64,7.80,8.52$, and 8.94 respectively.

The mean weighted developmental scores for each of the eight DSS grammatical categories are represented in Table III. The total group mean weighted developmental score for each category was: indefinite pronouns, 54.55: personal pronouns, 76.65 ; main verbs, 103.98 ; secondary 
TABLE II

RANGE AND PERCENTILES OF DSS SCORES FOR FORTY SUBJECTS BY THREE-MONTH AGE GROUPS

\begin{tabular}{ccccccccc}
\hline \hline \multirow{2}{*}{ Age Groups } & N & Range & \multicolumn{5}{c}{ Percentiles } \\
& & & 10th & 25 th & 50 th & 75 th & 90 th \\
\hline $5.0-5.2$ & 10 & $5.76-9.62$ & 5.76 & 6.64 & 6.90 & 8.30 & 8.40 \\
$5.3-5.5$ & 10 & $4.41-7.72$ & 4.41 & 5.46 & 6.24 & 7.32 & 7.36 \\
$5.6-5.8$ & 10 & $6.06-9.16$ & 6.06 & 7.62 & 8.20 & 8.52 & 8.92 \\
$5.9-5.11$ & 10 & $8.12-9.16$ & 8.12 & 8.42 & 8.70 & 8.94 & 9.14 \\
$5.0-5.11$ & 40 & $4.41-9.62$ & 5.74 & 6.64 & 7.80 & 8.52 & 8.94
\end{tabular}

verbs, 18.08 negatives, 21.95 ; conjunctions, 39.68; interrogative reversals, $12.45 ;$ and Wh-questions, 8.26 . The mean number of sentence points assigned for the total group was 42.33, which is also shown in Table III.

Table IV presents the combined mean developmental score for each of the eight grammatical categories, based on 50 utterance samples for 40 children. The combined mean developmental score for each grammatical category was: indefinite pronouns, 2.02; personal pronouns, 7.72; main verbs, 2.06; secondary verbs, 2.96 ; negatives, 5.02; conjunctions, 3.68 ; interrogative reversals, 3.61 and Wh-questions, 2.99 .

The descriptive statistics presented in Tables I through IV provide the answer to the first research 


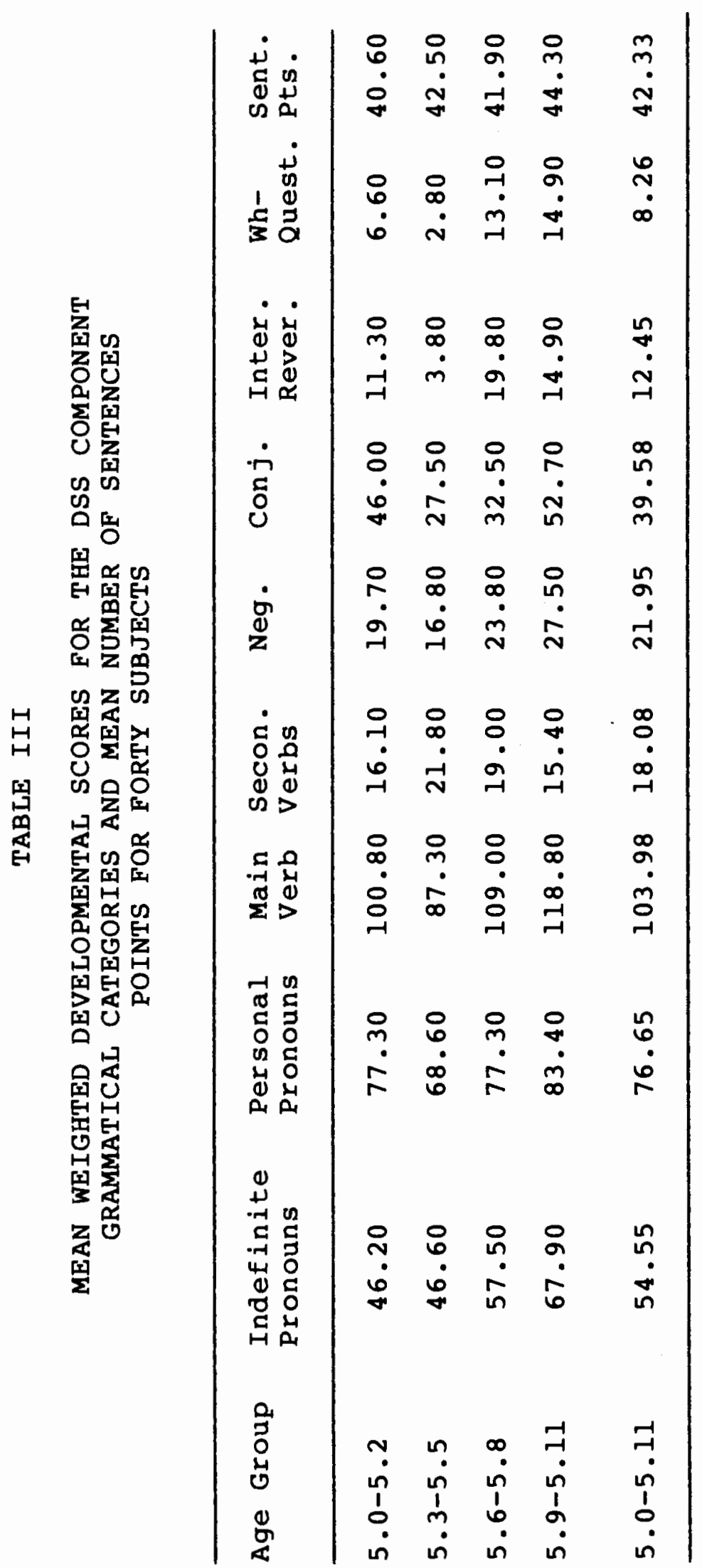




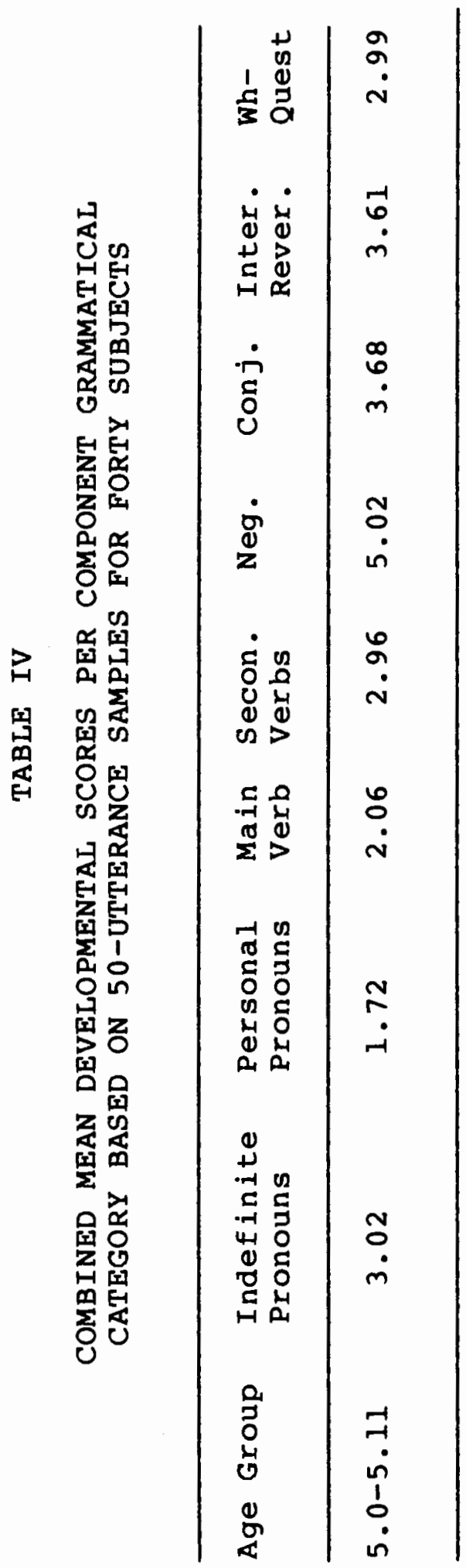


question.

The second research question was: Is there a significant difference between the mean DSS score obtained in Portland, Oregon, and that obtained in the Midwest by Lee (1974) and reported by Koenigsknecht (1974)? A two-tailed $\underline{t}$-test was applied to the data according to procedures presented by Bruning and Kintz (1977) to determine if a significant difference exists between the means of the two studies. Table $v$ demonstrates that the result of $\underline{t}$ of 2.042 showed a statistically significant difference beyond the .05 level of confidence occurred between the two different geographical means, with the Midwest sample obtaining a higher mean DSS score. The DSS mean for the Midwest sample was 9.19 , as compared to the mean of 7.61 for the Portland sample.

\section{TABLE V}

A COMPARISON OF THE DSS MEANS AND STANDARD DEVIATIONS OBTAINED IN THE MIDWEST AND PORTLAND FOR 5-YEAR OLDS

$\begin{array}{llll}\substack{\text { Geographical } \\ \text { Location }} & \text { Mean } & \text { S.D. df } & t \frac{t}{\text { est }}\end{array}$

$\begin{array}{llllll}\text { Midwest (1974) } & 9.19 & 1.90 & & & \\ \text { Portland (1985) } & 7.61 & 1.25 & & & \end{array}$

Additional differences were evident when comparing the results of the two geographically different studies. 
Table VI shows a comparison between the overall range of DSS scores and the percentile values. The Portland range was more restricted with both extremes being lower than those in the Midwest study, and each percentile value in the Portland study was lower than the Midwest study.

\section{TABLE VI}

A COMPARISON OF THE RANGES AND PERCENTILES OF DSS SCORES FOR THE MIDWEST AND PORTLAND, OREGON FOR CHILDREN 5.0 THROUGH 5.11 YEARS

\begin{tabular}{|c|c|c|c|c|c|c|c|}
\hline $\begin{array}{l}\text { Georgraphical } \\
\text { Location }\end{array}$ & $\mathbf{N}$ & Range & $10 \mathrm{th}$ & $\begin{array}{l}\text { Percen } \\
25 \text { th }\end{array}$ & $\begin{array}{l}\text { atiles } \\
50 \text { th }\end{array}$ & 75 th & $90 \mathrm{th}$ \\
\hline Midwest & 40 & $6.04-13.40$ & 6.72 & 7.89 & 9.19 & 10.49 & 11.66 \\
\hline Portland & 40 & $4.41-9.62$ & 5.74 & 6.64 & 7.80 & 8.52 & 8.9 \\
\hline
\end{tabular}

Lee (1974) suggests that a child's language performance can be compared to that of his/her peers by plotting the child's DSS score on the "Norms for Developmental Sentence Scoring" graph (Appendix F). This graph is used to determine percentile levels with which clinical decisions can be made. Following the plotting procedure, each of the 40 DSS scores was plotted using Lee's percentile values and the percentile values determine in the Portland sample. As shown in Table VII, all but three of the individual DSS scores in the Portland sample were assigned to lower percentile levels when using the Midwest norms, 
TABLE VII

A COMPARISON OF THE NUMBER OF SUBJECTS PER PERCENTILE LEVEL USING MIDWEST NORMS AND PORTLAND, OREGON, NORMS

\begin{tabular}{|c|c|c|c|c|c|c|c|c|}
\hline \multirow{2}{*}{$\begin{array}{l}\text { Geographical } \\
\text { Location }\end{array}$} & \multirow{2}{*}{$\begin{array}{l}\text { Age } \\
\text { Range }\end{array}$} & \multirow{2}{*}{$\begin{array}{l}\mathbf{N} \\
\text { of } \\
\text { SS }\end{array}$} & \multirow{2}{*}{$\begin{array}{l}\text { Below } \\
\text { loth }\end{array}$} & \multicolumn{3}{|c|}{ Percentiles } & \multirow[b]{2}{*}{$75 \mathrm{th}$} & \multirow[b]{2}{*}{90 th } \\
\hline & & & & loth & 25 th & 50 th & & \\
\hline $\begin{array}{l}\text { Midwest } \\
\text { (1974) }\end{array}$ & $5.0-5.2$ & 10 & 4 & 3 & 2 & 1 & 0 & 0 \\
\hline $\begin{array}{l}\text { Portland } \\
\text { (1985) }\end{array}$ & & & 0 & 2 & 4 & 3 & 0 & 1 \\
\hline Midwest & $5.3-5.5$ & 10 & 6 & 4 & 0 & 0 & 0 & 0 \\
\hline Portland & & & 3 & 3 & 4 & 0 & 0 & 0 \\
\hline Midwest & $5.6-5.8$ & 10 & 1 & 3 & 6 & 0 & 0 & 0 \\
\hline Portland & & & 0 & 1 & 2 & 4 & 3 & 0 \\
\hline Midwest & $5.9-5.11$ & 10 & 0 & 0 & 9 & 1 & 0 & 0 \\
\hline Portland & & & 0 & 0 & 0 & 3 & 5 & 2 \\
\hline \multicolumn{9}{|l|}{ Combined } \\
\hline Midwest & $5.0-5.11$ & 40 & 11 & 10 & 17 & 2 & 0 & 0 \\
\hline Portland & & & 3 & 6 & 10 & 10 & 8 & 3 \\
\hline
\end{tabular}

rather than the Portland norms.

Tables VIII and IX show the comparison of the mean weighted developmental scores for each grammatical category and sentence point component for the Midwest and Portland, Oregon samples. Koenigsknecht (1974) did not provide standard deviations for each grammatical category, 
making it impossible to test for a statistically significant difference between the category scores. Visual inspection of the data, however, presented in Table VIII indicates that the Portland children used a higher number of and/or more complex grammatical forms in the categories of negatives, interrogative reversals, and Wh-questions. The children in the Midwest study used a higher number of and/or more complex grammatical forms in the categories of indefinite pronouns, personal pronouns, main verbs, secondary verbs, and conjunctions. When comparing the mean number of sentence points assigned, the Portland sample received a higher mean $(+3.23)$ than the Midwest sample.

Table IX represents the complexity of grammatical forms per grammatical category used by children in both geographical locations. The data indicate that the Portland, Oregon, children used grammatical forms that were more complex in the negative, interrogative reversal, and Wh-question categories. The Midwest children used grammatical forms that were more complex in the other five categories, i.e., indefinite pronouns, personal pronouns, main verbs, secondary verbs and conjunctions.

In summary, Tables I through IV answer the first research question by providing the descriptive statistics for the Portland, Oregon, area. Table $V$ provides the answer to the second research question. A statistically significant difference does exist between the mean DSS scores derived for the two different geographical locations 


\section{TABLE VIII}

A COMPARISON OF THE MEAN WEIGHTED DEVELOPMENTAL SCORES ON THE DSS COMPONENT GRAMMATAICAL CATEGORIES AND THE MEAN NUMBER OF SENTENCE POINTS FOR FORTY SUBJECTS BY GEOGRAPHICAL LOCATION

\begin{tabular}{lccc}
\hline $\begin{array}{l}\text { Grammatical } \\
\text { Category }\end{array}$ & $\begin{array}{c}\text { Mean } \\
(1974)\end{array}$ & $\begin{array}{c}\text { Portland } \\
(1985)\end{array}$ & Difference \\
\hline Indefinite Pronouns & 68.35 & 54.55 & -13.80 \\
Personal Pronouns & 108.42 & 76.65 & -31.77 \\
Main Verbs & 139.20 & 103.98 & -35.02 \\
Secondary Verbs & 21.72 & 18.08 & -3.64 \\
Negatives & 13.75 & 21.95 & +8.20 \\
Conjunctions & 61.32 & 39.68 & -21.64 \\
$\begin{array}{l}\text { Interrogative } \\
\text { Reversals }\end{array}$ & 2.00 & 12.45 & +10.45 \\
Wh-Questions & 4.82 & 8.26 & +3.44 \\
Sentence Points & 39.10 & 42.33 & +3.23 \\
\hline
\end{tabular}

of Portland and the Midwest. Additionally, Tables VI through IX present differences between the ranges, percentile levels, and mean weighted developmental scores per grammatical category for the two locations. The following discussion will review some of the variables which may have influenced the results of the present study.

Literature pertaining to oral language sampling has proposed that many variables may affect oral language 
TABLE IX

A COMPARISON OF THE MEAN DEVELOPMENTAL SCORES

PER DSS COMPONENT GRAMMATICAL CATEGORY

BY GEOGRAPHICAL LOCATION

\begin{tabular}{lccc}
\hline $\begin{array}{l}\text { Grammatical } \\
\text { Category }\end{array}$ & $\begin{array}{c}\text { Mean } \\
(1974)\end{array}$ & $\begin{array}{c}\text { Portland } \\
(1985)\end{array}$ & Difference \\
\hline Indefinite Pronouns & 2.12 & 2.20 & +0.10 \\
Personal Pronouns & 2.06 & 1.72 & +0.34 \\
Main Verbs & 2.12 & 2.06 & +0.06 \\
Secondary Verbs & 3.34 & 2.96 & +0.38 \\
Negatives & 4.94 & 5.02 & +0.08 \\
Conjunctions & 3.94 & 3.68 & +0.26 \\
$\begin{array}{l}\text { Interrogative } \\
\text { Reversals }\end{array}$ & 1.25 & 3.61 & -2.36 \\
Wh-Questions & 1.72 & 2.99 & -1.27 \\
\hline
\end{tabular}

\section{Discussion}

samples elicited from children. The effects of socioeconomic level, receptive vocabulary ability, stimulus materials, corpus collection, environment, transcription and scoring onthecurrent study will now be discussed.

Socioeconomic level may impact oral language sampling as reported by Jones and McMillan (1973). They found that children from lower socioeconomic levels produce language made up of shorter and fewer units and fewer 
complex grammatical structures.

One of Lee's (1974) criteria for subject selection was that the children were to be from the middle socioeconomic class. Lee used the seven point warner scale for the rating of the parental occupations of her subjects to determine their socioeconomic level. In the present study, middle class status was determined by the occupation and education of the primary wage earner in the child's home, using the levels determined by the U.S. Bureau of Census (1963). The educational mean was 80.12. The range of occupational levels was 39 to 92 , with a mean of 67.50 . This represents a wide spectrum of middle class. The possibility that the inclusion of children from the lower end of the middle class continuum may have depressed the mean DSS score in the present study will be examined.

Tilden-Browning (1985) replicated Lee's 1974 study with children ages 6.0 through 6.11 years. Tilden-Browning proposed that including children from the lower end of middle class may have depressed the DSS scores found in her study. In order to explore this possibility, she divided her subjects into lower and upper middle class groups, and compared their respective DSS mean scores. The results indicated that a statistically significant difference did not exist between the DSS scores for the children from lower and upper middle class families. 
Tilden-Browning concluded that the inclusion of children from lower middle class families was not an influence on the overall depressed mean DSS score in her study. The occupational range and education levels in the present study are very similar to those reported by Tilden-Browning. It is surmised that the depressed DSS mean score found in the present study is also not attributable to the inclusion of the lower end of the middle class continuum. Another of Lee's (1974) criteria for subject selection was that a child's score on the Peabody Picture Vocabulary Test fall within one standard deviation from the mean for his/her age level. Using the same criterion, only children whose scores fell within the standard score range of 85 to 115 were included in the current study. The same receptive vocabulary ability range was used in both studies, therefore, the variable of discrepancies between the receptive vocabulary skills of the 40 subjects does not appear to be accountable for the depressed ovrall mean DSS score in the present study.

The effect of stimulus materials used to elicit language samples has been the topic of many investigations, as reviewed in Chapter II. Stimulus materials similar to those used by Lee (1974) were used in the current study, in order to control for this variable. Lee used a small barn and farm animals, a doll family and furniture, a transport truck and cars; story action 
pictures from the preprimer series, We Read Pictures, We Read More Pictures, and Before We Read (Robinson et al., $1962 a, b, c)$; and pictures from What's Its Name (Utley, 1950). With the exception of substituting pictures from the Game Oriented Activities for Learning (Karnes, 1972) for the preprimer pictures, this study used the same stimulus materials. It is improbable that the use of different pictures was a major influence on the individual scores, since the majority of the corpuses consisted entirely of utterances obtained during play with the toys.

Although the variable of stimulus materials was controlled, most of the corpuses selected were from utterances elicited during play with the toys. This may be one reason for the difference between the overall mean DSS scores of the two locations.

Lee (1974) recommends omitting the first utterances of the sample in order to avoid any possible periods of warm-up and adjustments by the child. She then indicates that the examiner should scan the sample and select the 50 consecutive utterances that represent the child's best language performance. In Lee's (1974) normative study, she chose to analyze the last 50 utterances obtained. Her reasons were twofold. First, she wanted to eliminate any period of warm-up, and secondly, she wanted to insure that the corpus contained all the utterances elicited during 
that the children produced their highest level of language during story re-telling, as opposed to playing with toys or looking at pictures. Lee contended that it is impossible for children to produce better language than their grammatical rules allow, but it is possible for them to speak more simply and immaturely than their capabilities. In selecting the utterances from the story re-telling for analysis, Lee was attempting to assure that the children's performances reflected their true grammatical competence. When reviewing the "Three Bears" utterances in the present study, it became evident that the children's DSS scores may have been higher had the "Three Bears" utterances been included in the corpus.

Tilden-Browning (1985) also observed this difference when examining the language samples of 6-year old children. She attributed the difference to her observation that the children seemed to be producing rote sentences, and suggested that the more sophisticated structures used by the children were not actually within their grammatical repertoire. One example of this phenomenon occurs when a child happens to remember the word "somebody," which occurs in most renditions of the "Three Bears." "Somebody" receives three DSS points in the indefinite pronoun category, and each of the three bears uses the word "somebody" three times, so the child could possibly receive 27 points 
for a structure that may not truly be his/her grammatical repertoire. Even if the child is competent with the use of "somebody," it is unlikely that he/she would use it in nine almost-consecutive utterances.

In the present study with 5-year old children, it was noted that the children did not produce primary and secondary verbs correctly in uttterances elicited in story re-telling, if they had not produced them correctly in utterances elicited with toys. In other words, the memorization factor did not apepar to apply to the verb categories.

Another difference noted when comparing the toy and "Three Bears" utterances was their corresponding mean length of response scores. Short, elliptical utterances were more typical of the toy elicited samples, whereas the children tended to elaborate and produce longer utterances during the "Three Bears" re-telling.

Mean Length of Response was calculated for fifteen toy elicited utterances and fifteen "Three Bears" elicited utterances for the 5.6 through 5.8 years age subgroup. This age subgroup was selected because none of their DSS corpus utterances included any elicited with the "Three Bears." The comparison of the MLR scores is shown in Table $\mathrm{x}$. Nine of the ten children produced higher MLR scores during the re-telling of the "Three Bears." The average increase in MLR score was 1.86 points. This may 
suggest that whether the children have memorized the story's grammatical structures or not, they may produce higher DSS scores as they approximate the story. The increased number of responses per utterance in the storytelling format may simply provide more opportunities for the child to produce higher scoring grammatical structures.

In the present study, the first ten utterances were omitted to allow for a warm-up period by the child, and the next 50 , consecutive utterances meeting all of Lee's (1974) criteria for corpus selection were used (Appendix G). It is possible that if the last 50 utterances per language sample had been selected, the mean DSS score for the Portland, Oregon sample would not have differed significantly from the Midwest sample. Whether the significant difference between the overall mean DSS scores may be attributable to the different corpus selections remains unknown. Results of a study comparing Lee's different sets of stimulus materials may provide more insight.

All 40 language samples were elicited in quiet school rooms according to Lee's (1974) elicitation criteria (Appendix F). This investigator used a variety of grammatical structures and avoided using questions and corrections. These procedures are consistent with the elicitation techniques used by Lee, and probably would not 
TABLE X

A COMPARISON OF MEAN LENGTH OF RESPONSE SCORES OBTAINED FROM FIFTEEN UTTERANCES

ELICITED WITH TOYS AND RE-TELLING

THE "THREE BEARS" FOR 10 SUBJECTS

AGE 5.6 TO 5.8 YEARS

\begin{tabular}{cllc}
\hline Subject & $\begin{array}{l}\text { Toys } \\
\text { MLR }\end{array}$ & $\begin{array}{l}3 \text { Bears } \\
\text { MLR }\end{array}$ & Difference \\
\hline 1 & 6.64 & 7.50 & +0.86 \\
2 & 6.76 & 6.72 & -0.04 \\
3 & 5.68 & 8.80 & +3.12 \\
4 & 6.88 & 9.24 & +2.36 \\
5 & 7.16 & 10.50 & +3.34 \\
6 & 4.36 & 4.50 & +0.14 \\
7 & 5.64 & 8.24 & +2.60 \\
8 & 7.16 & 8.88 & +1.72 \\
9 & 6.72 & 9.80 & +3.08 \\
10 & 5.36 & 6.76 & +1.40 \\
Group Mean & 6.23 & 8.09 & +1.86 \\
\hline
\end{tabular}


have differed enough in the current study to account for the difference in DSS scores.

Painstaking care was exercised in the transcribing, segmenting, and scoring of the language samples, with adherence to all procedures and guidelines recommended by Lee (1974, Appendixes $A, C, E)$. Lee's guidelines regarding segmentation and the use of "and" were carefully followed; however, the Portland sample's lower conjunction score may have been influenced by the sometimes subjective separating of utterances. Tilden-Browning (1985) also noted this pattern with her six year old subjects, which suggests that either both studies were influenced by segmentation judgments, or that a real difference exists between conjunction usage of children in the Midwest and Portland, Oregon.

Variables pertaining to subject selection which were not specifically controlled in this study, but may have had some affect on the reported difference between the overall mean DSS scores for Portland, Oregon, and the Midwest include: cultural differences; differences in parenting skills; parental values; the number of children who attended preschool; the availability and quality of educational services provided in the two different geographical regions; etcetera.

Differences other than mean DSS scores were noted in the descriptive statistics of the current study, when 
compared with Lee's original study (1974). Lee (1974) suggested that the mean DSS scores for the five one-year age groups displayed a quantifiable and linear increase in the grammatical complexity. This pattern was not found to be evident when examining only one year's progression (Table I). The oldest group ( 5.9 to 5.11 years) who would score the highest according to Lee, did, with a mean DSS of 8.70 . The next age group ( 5.6 to 5.8 years) scored the next highest with a DSS mean of 8.00 . The inconsistency occurred with the youngest age group (5.0-5.2 years), which scored third highest with a DSS mean of 7.42 , leaving the last group ( 5.3 to 5.5 years), with the lowest DSS mean of 6.33 . The ranking of the four age subgroups corresponds to their ranking of PPVT scores (Table XI). This may indicate that receptive vocabulary ability may have some correlation with expressive language skills in normally developing children, which influenced the DSS scores of this study's samples.

McCluskey (1984) replicated Lee's original normative study with children ages 4.0 to 4.11 , in Portland, Oregon. Tilden-Browning (1985) replicated the study with children ages 6.0 to 6.11 , in the Portland area. The three replications, including the current study, discovered differences in the mean developmental score per grammatical categories when compared to Lee's original study. All three studies indicated that the Portland area children 
TABLE XI

A COMPARISON OF MEAN DSS SCORES AND PPVT-R PERFORMANCE FOR EACH THREE-MONTH AGE SUBGROUP

\begin{tabular}{cccc}
\hline Ranking & $\begin{array}{c}\text { Age } \\
\text { Subgroup }\end{array}$ & $\begin{array}{c}\text { PPVT-R } \\
\text { Mean }\end{array}$ & $\begin{array}{l}\text { DSS } \\
\text { Mean }\end{array}$ \\
\hline 1 & $5.9-5.11$ & 103.80 & 8.70 \\
2 & $5.6-5.8$ & 101.70 & 8.00 \\
3 & $5.0-5.2$ & 100.00 & 7.42 \\
4 & $5.3-5.5$ & 98.70 & 6.33 \\
\hline
\end{tabular}

scored higher in the grammatical categories of negatives, interrogative reversals, and wh-questions. The three studies also agreed that the Portland area subjects scored lower in the indefinite pronouns, personal pronouns, and main verbs categories. The Portland area studies varied in only two grammatical categories: conjunctions and secondary verbs. The differences in these two categories of the Portland area studies could be attributed to many variables, e.g., the age of the subjects, slight differences in elicitation techniques, urban versus suburban location, etcetera. However, it would appear significant that three Portland area studies agreed in six of the eight grammatical categoreis (Table XII).

The three Portland area studies have concluded that 


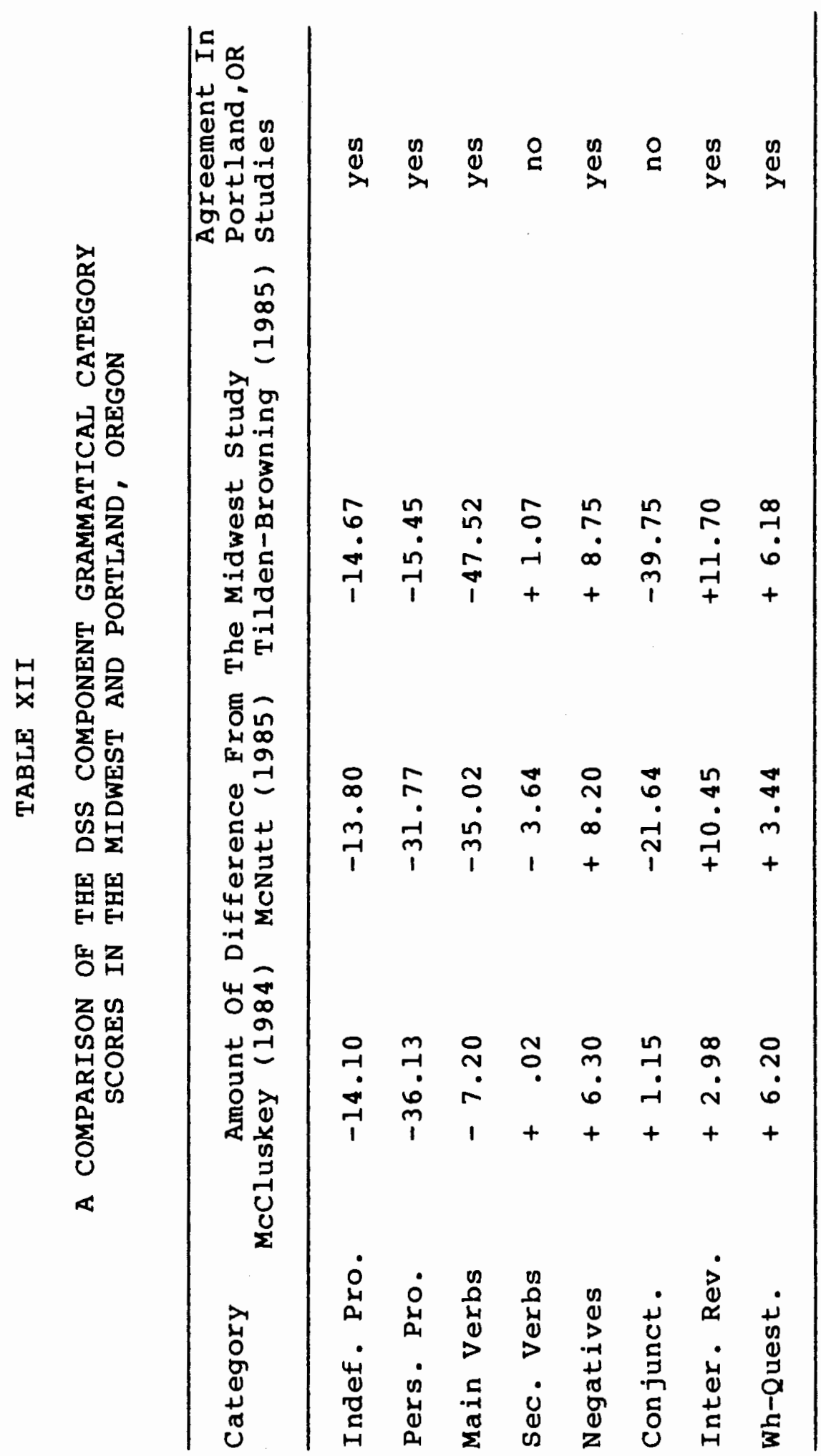


their respective mean DSS scores for each age group is lower than those reported by Lee (1974). The mean DSS scores from Lee's study, and the three Portland area studies are shown in Table XIII.

\section{TABLE XIII}

A COMPARISON OF THE MEAN DSS SCORES OBTAINED IN THE MIDWEST WITH THOSE OBTAINED IN OREGON

Location

Age Range 4.0-4.11 yrs 5.0-5.11 yrs 6.0-6.11 yrs

Midwest

(Lee, 1974)

8.04

9.19

10.94

Oregon

(McCluskey, 1984)

7.27

7.61

9.08

McNutt, 1985 )

T-Browning, 1985)

The similarity of the results in the Portland, Oregon studies appears to indicate that a geographical difference bettween the Midwest and oregon locations, does influence the DSS scores for children ages 4.0 through 6.11. Caution should be exhibited, however, in drawing such a conclusion. Certain variables need to be considered. McCluskey (1984), Tilden-Browning (1985), and the present investigator all received their Master's level education and clinical training at the same University. Philosophical and technical differences which could influence elicitation may exist between the oregon clinicians 
and those involved in the Midwest study. The three Oregon clinicians selected a corpus from primarily the toy elicited utterances, which varied somewhat from Lee's (1974) study. However, since all the clinicians inolved followed Lee's (1974) guidelines and procedures, and because location was the only variable that was systematically manipulated in the replication of Lee's study, geographical difference may have accounted for this difference in normative data. If a geographical difference does exist, it would be important for clinicians practicing outside the Midwest to develop a local normative data or to use the original Midwest DSS norms with extreme caution, as Lee has recommended. 
CHAPTER V

\section{SUMMARY AND IMPLICATIONS}

\section{Summary}

A review of the literature pertaining to oral language sampling reveals that clinicians have found a variety of procedures useful in determining the expressive language abilities of children. Some of the procedures have examined length of utterances (MLR, MLU), while others have analyzed the degree of grammatical complexity in a child's utterance (SCS, LDI, DSS).

The focus of this study was the DSS, developed by Lee and Canter (1971) and Lee (1974). The DSS is used to analyze a corpus of 50 utterances according to eight grammatical categories. Once a DSS score is determined for an individual child, that child's performance can be compared to that of his/her peers, using the normative data provided by Lee (1974) and reported by Koenigsknect (1974).

The DSS is widely used by clinicians and has been utilized in many research studies conducted throughout the United States. Mccluskey (1984) and Tilden-Browning (1985) replicated Lee's study in Portland, Oregon, with 
4-year old and 6-year old children, respectively. They both found their normative data differed from that established by Lee in the Midwest. Both McCluskey and TildenBrowning concluded that varying geographical locations may have explained the statistically significant differences in their respective results.

The present study sought to continue the investigation into the effect of geographic differences on the DSS scores of children ages 5.0 though 5.11 years. The purpose was to replicate Lee's (1974) study in order to determine if significant differences were also evident with a third age group included in Lee's normative population. A collateral purpose was to continue collecting data for Oregon, specifically for the Portland area. Forty children, chosen on the basis of chronological age ( 5.0 through 5.11 years), normal receptive vocabulary skills, normal hearing and monolingual background participated as subjects. A language sample of 50 utterances was elicited from each child and analyzed according to the DSS procedure. DSS means, standard deviations, percentiles, range of mean scores, mean weighted developmental score for each grammatical category and mean number of utterances earning a sentence point were compiled. A two tailed t-test was computed to determine if a difference exists between the means of the scores obtained in Portland, Oregon, and those obtained in the Midwest. 
The $\underline{t}$-test results indicated that a statistically significant difference between the mean DSS scores obtained in the two different locations did exist, which may be attributed to the geographical difference. A comparison of the two sets of normative data revealed that the mean of the Portland area children was loer than that of the Midwest children. Variables such as the inclusion of subjects from families whose primary wage earner occupational scores spanned the middle class continuum, the receptive vocabulary skills of the subjects and the type of stimulus materials used, do not appear to have significantly influenced the reported differences. Other variables may have had some affect on the results. The number of children in pre-school or the demographics of the given area may have differed from Lee's (1974) study. Differences in corpus selection, i.e., utterances obtained while playing with toys or utterances obtained during the retelling of "The Three Bears" may be a possible explanation for the differences in the two studies.

However, considering the similar variance from Lee's (1974) study found by Mccluskey (1984) and Tilden-Browning (1985) in Oregon, it appears that the geographic difference may indeed be responsible for the differences between the mean DSS scores of children living in Oregon and the Midwest. Caution must be exercised in regard to this point; all three clinicians were trained at the same 
University and their common clinical techniques may have influenced the results. One must also consider that the clinicians in the Midwest and in Oregon were all closely following Lee's guidelines for eliciting, transcribing and scoring the language samples, and that individual differences may not have been significant enough to influence the study. Therefore, since geogrpahic location was the only systematically manipulated variable, it is feasible that differences in DSS scores between the Midwest and Oregon may be attributable to the differences in geographic location.

\section{Implications}

\section{Clinical Implications}

Since geographic location was determined to be a plausible explanation for the difference between the oregon means and Midwest means in all three Oregon studies, it is important that clinicians use the original DSS normative data with caution in areas outside the Midwest.

In the three Oregon studies, the children's performance was assigned percentile values using both the oregon normative data and that of Lee (1974). The oregon children were consistently assigned lower percentile scores using Lee's normative data. This becomes critical when reviewing Lee's suggestion that children scoring near the 10th percentile level need further evaluation, and those 
falling below the loth percentile will require intervention. Using the percentile levels determined in the oregon studies, 16 of the 120 children would need further evaluation and 6 would require intervention. According to Lee's (1974) percentile levels, 25 would need further evaluation and 27 would require intervention. In times of ballooning caseloads, it would be very unfortunate to initiate intervention for 27 children and determine that only 6 were indeed in need of services.

In 1974, Lee suggested that the DSS may be too complicated to use as an initial diagnostic tool and that it may be used to determine the need for continued services. It appears that until local normative data is available, that the use of the DSS for monitoring an individual child's progress is more valid than using it as a comparative instrument.

\section{Research Implications}

This investigator is unaware of any test-retest reliability studies performed with the DSS. Reliability information would be valuable in determining the clinical usefulness of the DSS.

Replication of Lee's study with the age ranges of 2.0 through 2.11 and 3.0 through 3.11 would complete the set of DSS normative data for oregon. It would be interesting to know if a statistically significant difference exists between DSS means obtained in Oregon and the 
Midwest, in the remaining two age groups. Additional replications of Lee's study in various other geographical locations would assist in singling out the variable of location as the explanation for the difference in means. If geographic loction is not found to be the influential variable, other factors could be considered. Do elicitation techniques vary significantly between clinicians trained in different Universities? Does the corpus chosen for analysis significantly impact DSS scores, i.e., those consisting of utterances obtained during play with toys, looking at pictures or retelling the "Three Bears"? A comparison of the stimuli used would examine the possible memorization factor observed in the utterances elicited with the "Three Bears," and would determine if the story re-telling utterances are truly representative of the subjects' expressive language abilities. Would retelling a different story or telling of a personal event in a story-like manner alter the DSS scores? TildenBrowning (1985) suggested comparing DSS scores obtained in urban areas with those obtained in more rural settings, to determine if demographic differences may influence DSS scores.

The results of this study and the two other oregon studies would indicate that further research is necessary before the original DSS normative data can be used without reservation outside of the Midwest. The DSS is a well 
developed and valuable clinical tool and hopefully, research into its wide geographical application will continue. It would appear that only when local normative data is available to clinicians will the DSS be a valid tool to assess children's grammatical development. 
AHMEND, S.E. (1973). Linguistic analysis of children's speech: Effects of stimulus media on elicited samples. Unpublished Master's Thesis, Ransas State University. In S. Barrie-Blackley, C. Musselwhite and S. Rogister (Eds.), Clinical oral language sampling. Danville, IL: The Interstate Printers and Publishers, Inc.

BARRIE-BLACKLEY, S., MUSSELWHITE, C., and ROGISTER, S. (1978). Clinical oral language sampling. Danville, IL: The Interstate Printers and Publishers, Inc.

BERNSTEIN, B. (196I). Social class and linguistic development: a theory of social learning. In A.H. Halsey, J. Floud and A. Anderson (Eds.), Economy, education and society. New York: Macmillan.

BETTS, E.A. (1934). An evaluation of certain techniques for the study of oral composition. Research Studies in Elementary Schools, 9, 7-35. In S. BarrieBlackley, C. Musselwhite, and S. Rogister (Eds.), Clinical oral language sampling. Danville, IL: The Interstate Printers and Publishers, Inc.

BLAXLEY, L., CLINKER, M. and WARR-LEEPER, G. (1983). Two language screening tests compared with the DSS. Language, Speech and Hearing Services in the Schools, 14, 38-46.

BROWN, R. (1968). The development of wh-questions in child speech. Journal of Verbal Learning and Verbal Behavior, 7, 279-290.

BROWN, R. (1973). A first Language: Th early stages. Cambridge, MA: Harvard University Press.

BRUNING, J.L. and RINTZ, B.L. (1977). Computational handbook of statistics (2nd ed.). Glenview, IL: Scott, Foresman and Company.

BUTLER, R. (1972). Review of verbal language development scale. In 0 . Buros (Ed.), Seventh mental measurements yearbook. Hyland Park, NJ: Gryphan.

CARROW, E. (1974a). A test using elicited imitation in assessing grammatical structure in children. Journal of Speech and Hearing Disorders, 39, 437-444. 
CARROW, E. (1974b). Carrow elicited language inventory. Austin, TX: Learning Concepts.

CAZDEN, C.B. (1968). The acquisition of noun and verb inflections. Child Development, 39, 433-443.

CAZDEN, C.B. (1978). Review of the CELI. In O. Buros (Ed.), Eighth mental measurements yearbook. Hy and Park, NJ: Gryphan.

CHомSKу, N. (1957). Syntactic structures. The Hague: Mouton.

CHOMSKY, N. (1965). Aspects of the theory of syntax. Cambridge, MA: MIT Press.

COWAN, A.A., WEBER, J., HODDINOTT, B.A. and KLEIN, J. (1967). Mean length of spoken response as a function of stimulus, experimenter, and subject. Child Development, 38, 191-203.

DUNN, L. (1965). Peabody Picture Vocabulary Test. Circle Pines, MN: American Guidance Service.

DUNN, L. (1979). Peabody Picture Vocabulary Test (Rev. Ed.). Circle Pines, MN: Holt, Rinehart and winston.

ELLIOT, S.N. and BRETZING, B.H. (1980). Using and updating local norms. Psychology in the Schools, 17, 196-201.

ERVIN, S.M. and MILLER, W.R. (1963). Language development. In $H$. Stevenson, J. Ragan and C. Spiker (Eds.), Child psychology; the sixty-second yearbook of the National Society for the Study of Education. Chicago, IL: University of Chicago Press.

FUCHS, D., FUCHS, L.S., GARWICK, W. and FEATHERSTONE, N. (1983). Test performance of language handicapped children with familiar and unfamiliar examiners. Journal of Psychology, 114, 37-46.

GEERS, A. and MOOG, J. (1978). Syntactic maturity of spontaneous speech and elicited imitations of hearing impaired children. Journal of Speech and Hearing Disorders, 43, 380-391.

HAMMILL, D.D. and NEWCOMER, PK.L. (1982). Test of oral language development (I), Aust in, TX: PRO-ED. 
HASS, W.A. and WEPMAN, J.M. (1973). Constructional variety in the spoken language of school children. The Journal of Genetic Psychology, 122, 297-308.

JOHNSON, D.L. (L974). The influence of social class and race on language test performance and spontaneous speech of preschool children. Child Development, $44,517-521$.

JONES, P.A. and MCMILLAN, W.B. (1973). Speech characteristics as a function of social class and situational factors. Child Development, 44, $117-121$.

KARNES, M. (1972). Game oriented activities for learning. "Scenes around us." Springfield, MS: Bradley Co.

KLIMA, E, and BELLUGI, U. (1966). Syntactic regularities in the speech of children. In J. Lyons and R.J. wales (Eds.), Psycholinguistic papers. Edinburgh: Edinburgh University.

KOENIGSKNECHT, R. (1974). Statistical information on developmental sentence analysis. In L. Lee (Ed.), Developmental sentence analysis. Evanston, IL: Northwestern University Press.

KRAMER, C., JAMES, S., and SAXMAN, J. (1979). A comparison of language samples elicited at home and in the clinic. Journal of Speech and Hearing Disorders, $44,321-330$.

LABOV, W. (1970). The study of nonstandard English. National Council of Teachers of English Research Monograph, Champaign, IL.

LEE, L. (1974). Developmental sentence analysis., Evanston, IL: Northwestern University Press.

LEE, L. and CANTER, S. (1971). Developmental sentence scoring: A clinical procedure for estimating syntactic development in children's spontaneous speech. Journal of Speech and Hearing Disorders, $36,315-3 \overline{40}$.

LEONARD, L.B. (1972). What is deviant language? Journal of Speech and Hearing Disorders, 37, 427-446.

LONGHURST, T. and FILE, J. (1977). A comparison of developmental sentence scores from Headstart children collected in four conditions. Language, speech and Hearing Services in the Schools, 8, 54-64. 
LONGHURST, T.M. and GRUBB, S. (1974). A comparison of language samples collected in four situations. Language, Speech and Hearing Services in the Schools, 5, 71-78.

LONGHURST, T.M. and SHRANDT, T.A. (1973). Linguistic analysis of children's speech: a comparison of four procedures. Journal of Speech and Hearing Disorders, $38,240-249$.

LOVELL, K., HOYLE, H.W. and SIDALL, M.Q. (1968). A studY of some aspects of the play and language of young children with delayed speech. Journal of Child Psychology and Psychiatry, 9, 41-50.

LYMAN, H. (1965). Review of the PPVT. In O. Buros (Ed.), Sixth mental measurements yearbook. Hyland Park, NJ : Gryphan.

MCCARTHY, D.A. (1930). The language development of the pre-school child. University of Minnesota, Institute of Child Welfare, Monograph series LV. Minneapolis, MN: University of Minnesota Press.

MCCARTHY, D.A. (1954). Language development in children. In L. Carmichael (Ed.), Manual in child psychology. New York: Wiley.

MCCLUSKEY, K. (1984). Developmental Sentence Scoring: A comparative study conducted in Portland, Oregon. Unpublished Master's thesis, Portland State University.

MCLOUGHLIN, J.A. and LEWIS, R.B. (1981). Assessing special students: Strategies and procedures. Columbus, OH: Charles E. Merrill.

MCNEIL, D. (1970). The acquisition of language: The study of developmental psycholinguistics. New York: Harper and Row.

MINER, L.E. (1969). Scoring procedures for the Length and Complexity Index: A preliminary report. Journal of Comunication Disorders, 2, 224-240.

MINIFIE, F.D., DARLEY, F.L. and SHERMAN, D. (1963). Temporal reliability of seven language measures. Journal of Speech and Hearing Research, 6, 139-147. 
MINTUN, S. (1968). An evaluation of three stimulus methods for eliciting verbal language samples from educably mentally handicapped children. Unpublished Master's thesis, Eastern Illinois University. In $S$. Barrie-Blackley et al. (Eds.), Clinical oral language sampling. Danville, IL: The Interstate Printers and Publishers, Inc.

MUELLER, E. (1972). The maintenance of verbal exchanges between young children. Child Development, 43, 930-938.

MUSSELWHITE, C.F. (1975). Three variations of the imperative format of language sample elicitation. Unpublished Master's thesis, University of North Carolina at Chapel Hill. In S. Barrie-Blackley et al. (Eds.), Clinical oral language sampling, Danville, IL: The Interstate Printers and Press, Inc.

NICE, M. (1925). Length of sentences as criterion of a child's progress in speech. Journal of Educational Psychology, $16,370-379$.

ROBINSON, H.M., MONROE, M. and ARTLEY, A.S. (1962a). Before we read. Chicago, IL: Scott Foresman. PP. $1,2,4,10,11,14,16$.

ROBINSON, H.M.,MONROE, M. and ARTLEY. A.S. (1962b). We read pictures. Chicago, IL: Scott Foresman, PP. 1,2 .

ROBINSON, H.M., MONROE, M. AND ARTLEY, A.S. (1962C). We read more pictures. Chicago: IL: Scott Foresman, Pp. 4, 16, 20, 28.

SHATZ, M. and GELMAN, R. (1973). The development of communication skills: Modifications in the speech of young children as a function of listener. Monographs of Society for Research in Child Development, 38 , No. 152 .

SIEGEL, G.M. (1962). Interexaminer reliability for the mean length of response. Journal of Speech and Hearing Research, 5, 91-95.

SMITH, D.R. (1970). The effect of four common patterns and sex on length of verbalization in speech of four year old children. (Final Report, office of Economic Opportunity, Contract No. B99-4980). In S. BarrieBlackley et al. (Eds.), Clinical oral language sampling. Danville, IL: The Interestate Printers and Press, Inc. 
STALNAKER, L.C. and GREAGHEAD, N.A. (1982). An examination of language samples obtained in three experimental conditions. Lanquage Speech and Hearing Services in the schools, 13, 12-127.

TEMPLIN, M.C. (1957). Certain language skills in children. Minneapolis, MN: University of Minnesota Press.

TILDEN-BROWNING, S.A. (1985). A comparative study of the Developmental sentence Scoring normative data obtained in Canby, Oregon, and the midwest, for children bvetween the ages of 6.0 and 6.11 years. Unpublished Master's thesis, Portland State Unviersity.

U.S. BUREAU OF THE CENSUS. (1963). Methodology and scores of socioeconomic status. Working paper No. 15, Washington, D.C.

UTLEY, J. (1950). What's its name? "The three bears." Urbana, IL: University of IIlinois Press.

VALENCIANO, M. (1981). Developmental Sentence Scoring sample size comparison. Unpublished Master's thesis, Portland state University.

WARNER, W.L., MEEKER, M. and ELLIS, K. (1949). Social class in America. Chicago, IL: Science Research Associates.

WATSON, B. (1976). Three variations of verbal stimuli with a play house task for language sample elicitation. Unpublished Master's thesis, University of North Carolina at Chapel Hill. In S. Barrie-Blakley, et al. (Eds.), Clinical oral language sampling. Danville, IL: The Interstate Printers and Publishers, Inc.

WINITZ, H. (1959). Language skills of male and female kindergarten children. Journal of Speech and Hearing Research, 2, 377-386. 


\section{APPENDIX A}

RULES FOR SEPARATING AND COMBINING SENTENCES

1. Interjections and nouns in direct address do not carry a DSS score, so they do not have to be separated out.

2. Question markers must be noted because questions receive a DSS score.

3. Imperative interjections, "look," "look it," and "see" and sentence tags, "you know," "I think," "I guess," etc. are separated out and given status.

Concerning Conjunctions:

1. Sentences which begin with conjunctions are counted as complete sentences, but the initial conjunction is not scored.

2. Only one "and" conjunction per sentence is allowed when the "and" connects two independent clauses.

3. The conjunction "and" used in a series, a compound subject, or a compound predicate does not require the sentence to be broken up.

4. Internal conjunctions other than "and" do not require a sentence to be broken up.

5. At the clinician's discretion, the rules for "and" may be applied to any other over-used conjunction.

If a child's sample contains both a pre-sentence structure and a complete sentence, a separation is made if the sentence is an independent clause; the fragment and the conjunction would be deleted and only the independent clause would be scored. For exmaple, "Over there but it's too far." ". . . it's too far." would be scored.

(from Lee, Developmental Sentence Analysis, 1974). 
I agree to allow my child to participate as a subject in the study entitled "A Comparative Study of Developmental Sentence Scoring Normative Data." This study will be conducted by Eileen McNutt under the supervision of Mary Gordon, thesis director, Speech and Hearing Sciences, Portland State University.

The purpose of this study is to compare scores obtained from language samples in the Portland area to scores used in normative data collected in the Midwest.

There are no risks or dangers inherent in the procedures of the study. My child will be given a hearing screening, a picture vocabulary test, and then will simply participate in conversation with Eileen McNutt. I understand that my child's name and performance results will remain confidential. I am free to withdraw my child from the study at any time.

Signataure of Parent/Guardian
$\overline{\text { Date }}$
Child's Birthdate

The following information will be helpful in describing the sample:

Current or most recent occupation of primary wage earner:

Years of education of primary wage earner:

Please return this form with your child tomorrow, indicating your approval. If you have any questions, I can be contacted at Jennings Lodge School (654-2838) or Gaffney Lane School (654-2441). Thank you. Eileen McNutt 


\section{DEVELOPMENTAL SENTENCE SCORING CATEGORIES AND REWEIGHTED SCORES}

\begin{tabular}{|c|c|c|c|c|}
\hline scokt: & $\begin{array}{l}\text { IMDEFINITE PKONOUNS } \\
\text { OR NOUN MODIFIERS }\end{array}$ & $\begin{array}{l}\text { PERSONAL } \\
\text { PRONOUNS }\end{array}$ & MAIN VERBS & SECONDARY VERBS \\
\hline 1 & ji, this,dhat & $\begin{array}{l}\text { Ist and 2nd person: I. } \\
\text { me, my, mine,you. } \\
\text { your(s) }\end{array}$ & 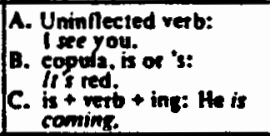 & \\
\hline 2 & & $\begin{array}{l}\text { 3rd pereon: he, him, his. } \\
\text { she, het, hers } \\
\text {. }\end{array}$ & 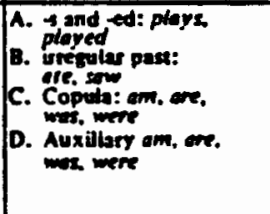 & 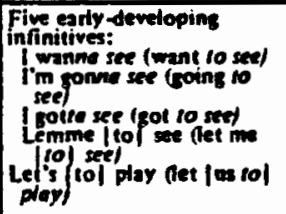 \\
\hline 3 & 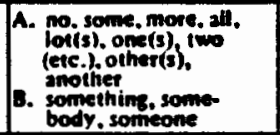 & $\begin{array}{l}\text { A. Fiurals we. us. our(s) } \\
\text { B. they, them, their } \\
\text { these those }\end{array}$ & & $\begin{array}{l}\text { Non eomplementing } \\
\text { infinitives: } \\
\text { istopped to plap. } \\
\text { ism al raid to look. } \\
\text { it's hard to do that. }\end{array}$ \\
\hline 4 & $\begin{array}{l}\text { nothing, nobody, nome, } \\
\text { no one }\end{array}$ & & 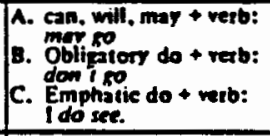 & $\begin{array}{l}\text { Participie, present of paut: } \\
\text { I see a boy runnifre } \\
\text { I found the toy broken. }\end{array}$ \\
\hline 5 & & $\begin{array}{l}\text { Retlexives: myself, your- } \\
\text { self, himseif. hersel. } \\
\text { itself, themsedves }\end{array}$ & 1 & 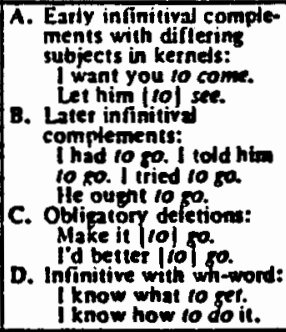 \\
\hline 6 & & 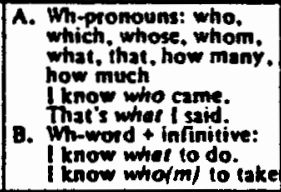 & 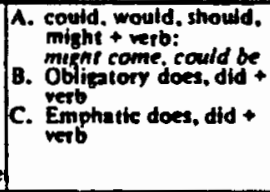 & \\
\hline 7 & 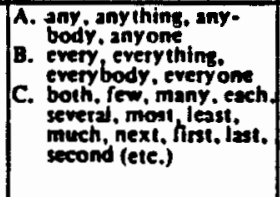 & \begin{tabular}{|l} 
(his) own, one, oneself. \\
whichever, whoeves, \\
whaleve? \\
Take wheterer you like. \\
-
\end{tabular} & 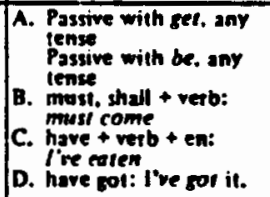 & $\begin{array}{l}\text { Passive infinitiva } \\
\text { complement: } \\
\text { will gef: } \\
\text { lhave io get dressed. } \\
\text { lon i want so get hur. } \\
\text { with be: } \\
\text { l want } 10 \text { be pulled. } \\
\text { li's going ro be locked. }\end{array}$ \\
\hline 8 & & & $\begin{array}{l}\text { A. have been + verb + } \\
\text { ing been + verb + ing } \\
\text { had been } \\
\text { B. modal + have + verb } \\
\text { c. modal + be + verb + } \\
\text { ing: } \\
\text { coild be playing } \\
\text { D. Other auxiliary } \\
\text { combinations: } \\
\text { should have been } \\
\text { deeping }\end{array}$ & $\begin{array}{l}\text { Gezund: } \\
\text { Swinking is fun. } \\
\text { lilke fishing. } \\
\text { lie started loughing. }\end{array}$ \\
\hline
\end{tabular}




\begin{tabular}{|c|c|c|c|c|}
\hline SCORE: & NEGATIVES & CONIUNCTIONS & $\begin{array}{c}\text { INTERROGATIVE } \\
\text { REVERSALS }\end{array}$ & WHIQUESTIONS \\
\hline 1 & 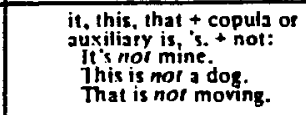 & & $\begin{array}{l}\text { Revercal of copula: } \\
\text { isn't if red? Were they } \\
\text { there? }\end{array}$ & \\
\hline 2 & & & & 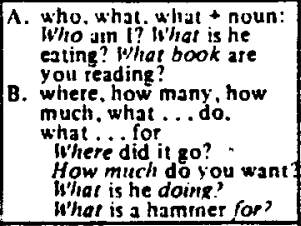 \\
\hline 3 & & and & & \\
\hline 4 & $\operatorname{can}$ 't.don't & & $\begin{array}{l}\text { Reversal of auxiliary be: } \\
\text { Is he coming? Jsn the } \\
\text { coming? lios he going? } \\
\text { Wasn't il going? }\end{array}$ & \\
\hline 5 & isn'l, won't & $\begin{array}{l}\text { A. but } \\
\text { B. so. and so, so that } \\
\text { C. or. if }\end{array}$ & & $\begin{array}{l}\text { When, how how + adjective } \\
\text { when hall come? } \\
\text { How do you do it? } \\
\text { How big is it? }\end{array}$ \\
\hline 6 & & because & 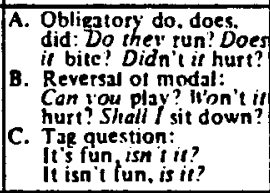 & \\
\hline 7 & 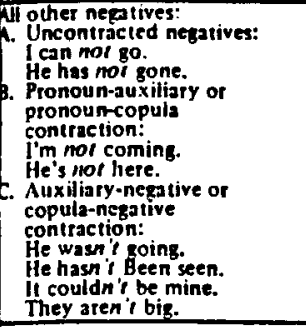 & & (1) & $\begin{array}{l}\text { why what if how come } \\
\text { how sbout i gerund } \\
\text { thy are you crying? } \\
\text { What if ion't do if? } \\
\text { How come he is cry ing? } \\
\text { How obout coming with me }\end{array}$ \\
\hline 8 & & 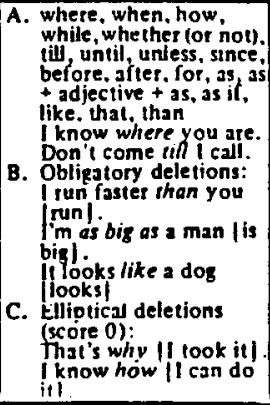 & 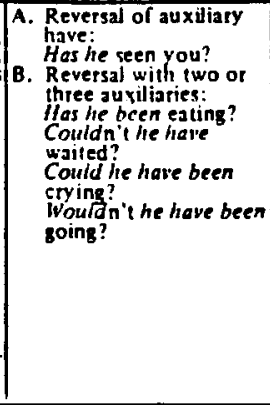 & $\begin{array}{l}\text { Whose. which. Which + noun } \\
\text { Whose car is that? } \\
\text { which book do you want? }\end{array}$ \\
\hline
\end{tabular}

(from Lee, Developmental Sentence Analysis, 1974). 


\begin{abstract}
APPENDIX D
LEE'S GUIDELINES FOR THE ELICITATION OF ORAL LANGUAGE SAMPLES
\end{abstract}

1. Use appropriate stimulus materials. In selecting stimulus materials, one should consider the child's age, sex, interests, intellectual level, and severity of handicap.

2. Try to elicit high-level grammatical forms. One should use high-level grammatical forms such as past tense, modal verbs, plural pronouns, etc., so that the child has an opportunity to use them himself in response.

3. Try to elicit complete sentences. When a child is not talking, one may resort to questions such as "What's this?," "What color is this?," and "Where is the boy?." Questions such as these may elicit short answers some of the time, however, they may also elicit single-word responses. One should discontinue using such questions as soon as possible. Often if one interacts with or talks about the stimulus materials without demanding a response from the child, the child will spontaneously respond.

4. Repeat what the child says. By repeating what the child says, one may clarify what the child said, as well as produce an invaluable guide for transcription.

(from Lee, Developmental Sentence Analysis, 1974). 
1. If a structure is attempted but lacks some feature of standard English, then an "attempt" mark, a line, is inserted in place of the numerical score.

2. A score of 1 is added in the column labeled "sentence point: for every sentence which meets all adult standard rules. Any attempt mark within the sentence will automatically require withholding of the sentence point. The sentence point could also be withheld for any attempt on a grammatical structure not included in the eight categories under consideration (e.g. the omission of articles or prepositions). The sentence point would also be withheld for semantic irregularities.

3. Indefinite Pronouns: the same score is given whether a word is used as a pronoun or a noun modifier.

4. Personal Pronouns: grouped according to person: Score 1 lst and 2 nd person: $I$, me

2 3rd person: he, she

3 Plurals: we, us, they

4

5 Reflexives: myself, herself, etc.

6 Wh- pronouns, who, which

7 (his) own, one, oneself: One hopes for peace.

5. Main Verbs:

Score I a. uninflected verb: I see you.

b. copula, is or 's: It's red.

c. -s tverbting: He is coming.

2 a. -s and -ed: plays, played

b. irregular past: ate, saw

3

c. copula: am, are, was, were

4 a. can, will, may+verb: may go

b. obligatory dotverb: don't go

5

c. emphatic dotverb: I do see.

6 a. could, would, should, might+verb: might come

b. obligatory does, did+verb

c. emphatic does, did+verb 
7 a. passive with get, any tense passive with be, any tense

b. must, shall+verb+en: I've eaten

c. havetverbten: I've eaten

d. have got: I've got it.

Occasional deletions in verb forms are part of adult standard English and should not be regarded as

immaturities in children's language. For example, if the clinician asks, "Does your mother work?" the child may answer, "No, she doesn't." Such elliptical verb forms are not given a score on the DSS; the abbreviation for "incomplete," "inc" is inserted on the record sheet in place of either a score or an attempt mark. Since adult grammatical rules contain elliptical verb forms, the sentence point is allowed.

6. Secondary Verbs

Score 1

2 Five early developing infinitives:

I wanna see (want to see)

I'm gonna see (going to see)

I gotta see (got tosee)

Lemme (to) see (let me (to) see)

Let's (to) play (let us (to) play)

3 Noncomplimenting infinitives

I stopped to play.

I'm afraid to look

It's hard to do that.

4 Participle, present or past:

I see a boy running.

I found the toy broken

5 a. Early infinitives with differing subjects in basic sentences:

I want you to come.

Let him (to) see.

b. Later infinitive complements:

I had to go. I told him to go.

I tried to go. He ought to go.

c. Obligatory deletions:

Make it (to) go.

I'd better (to) go.

d. Infinitive with wh-word:

I know what to get.

I know how to do it.

6

7 Passive infinitive:

with get: I have to get dressed.

I don't want to get hurt.

with be: I want to be pulled.

It's going to be locked 
8 Gerund:

Swinging is fun.

I like fishing.

7. Negative

He started laughing.

Score 1 it, this, that+copula or auxilliary is, 's,

+ not:

It's not mine.

This is not a dog.

2

That is not moving.

3
4
5
6
7

can't, don't

isn't, won't

All other negatives:

a. Uncontracted negataives;

I can not go.

He has not gone.

b. Pronoun-auxilliary or pronoun-copula contraction:

I'm not coming.

He's not here.

c. Auxlliary-negative or copula-negative contraction:

He wasn't going.

He hasn't been seen.

It couldn't be mine.

They aren't big.

8. Conjunction

score 1

2

3 and

4

5

6 because

7

8 a. where, when, how, while, whether (or not), till, until, unless, since, before,

after, for, as, astadjectivet as, as if,

like, that, than,

I know where you are.

Don't come till I call.

b. Obligatory delections:

I run faster than you (run).

I'm as big as a man (is big).

It looks like a dog (looks).

c. Elliptical deletions (score 0 )

That's why (I took it.

I know how (I can do it). 


$$
\begin{aligned}
& \text { Wh-words t infinitive } \\
& \text { I know how to do it. } \\
& \text { I know where to go. }
\end{aligned}
$$

9. Interrogative Reversal

Score 1 Reversal of copula:

2

Isn't it red? Where they there?

3

4 Reversal of auxilliary be:

Is he coming? Isn't he coming?

5

Was he going? Wasn't he going?

6 a. Obligatory-do, -does, -did:

Do they run? Does it bite?

Didn't it hurt?

b. Reversal of modal:

Can you play? Won't it hurt?

Shall I sit down?

c. Tag question:

$$
\text { It's fun, isn't it? }
$$

It isn't fun, is it?

7

8 a. Revrsal of auxilliary have;

Has he seen you?

b. Reversal with two or three auxilliaries:

Has he been eating?

Couldn't he have waited?

Could he have been crying?

Wouldn't he have been going?

10. Wh-questions

Score 1

2 a. who, what, what+noun

Who am I? What is he eating?

What book are you reading?

b. where, how many, how much, what... do what. . . for

Where did it go?

How much do you want?

What is he doing?

what is a hammer for?

3

4

5 when, how, how adjective When shall I come?

How do you do it?

How big is it? 
7 why, what if, how, come, how about+gerund Why are you crying?

What if I won't do it

How come he is crying?

How about coming with me?

8 whose, which, which+noun

Whose car is that?

Which book do you want?

Deriving the Developmental Sentence Score:

When all fifty sentences in the language sample have been individually scored, the mean sentence score is derived by adding the total sentence scores and dividing by fifty. This is known as the child's DSS.

(from Lee, Developmental sentence Analysis, 1974). 
LEE'S "NORMS FOR DEVELOPMENTAL SENTENCE SCORING"

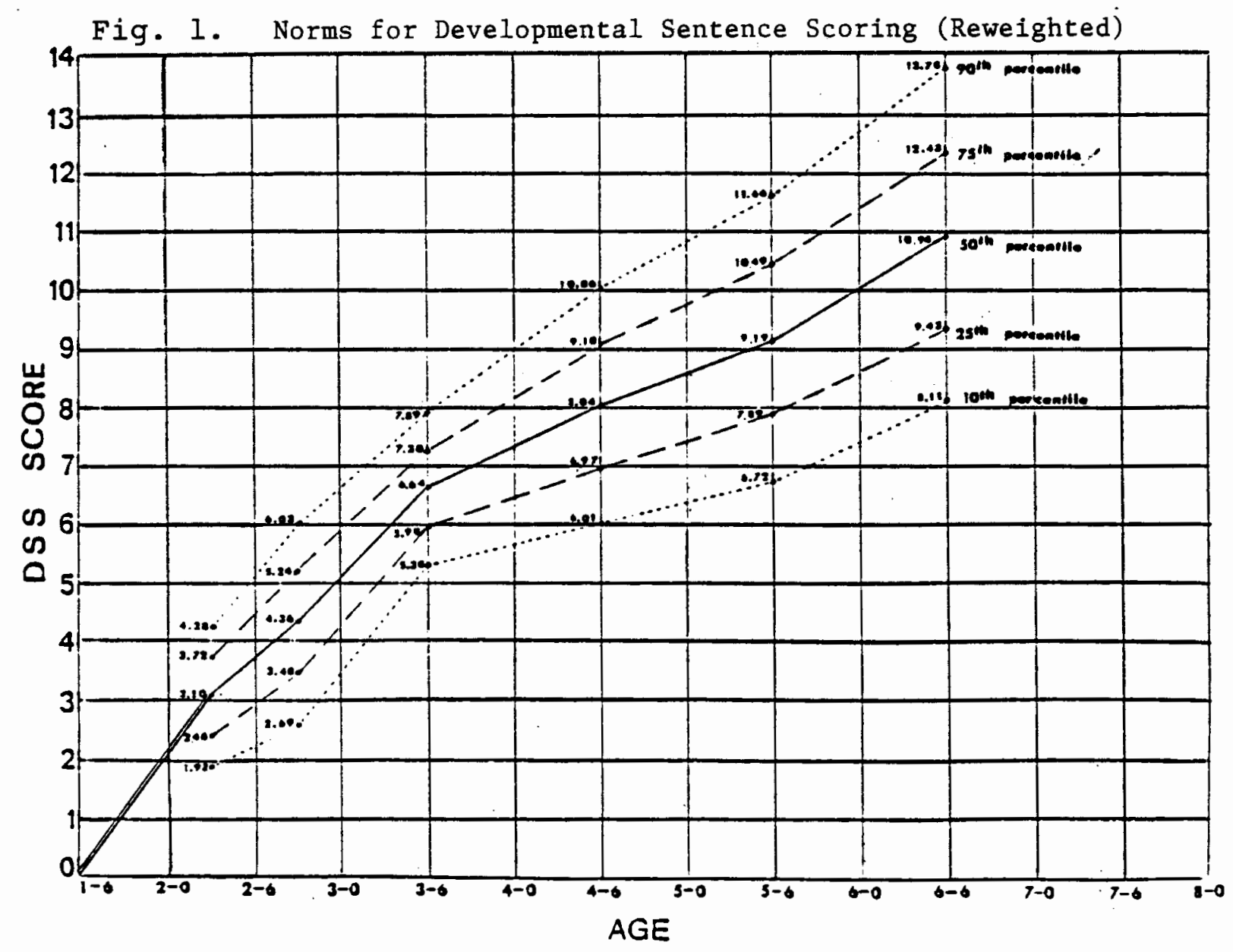

(from Lee, Developmental Sentence Analysis, 1974). 


\section{APPENDIX G}

LEE'S CRITERIA FOR SELECTING THE CORPUS FOR GRAMMATICAL ANALYSIS

1. The corpus should consist of fifty complete sentences. A complete sentence contains a noun/pronoun and verb in subject-predicate relationship. A sentence does not need to be gramatically complete or correct. The following sentences would be considered complete:

"It's cold."

"Mommy washing dishes." (lexical V washing present although auxiliary verb is missing)

"Stop doing that!" (imperative sentence with subject you understood)

The following sentences would be considered incomplete:

"Daddy home last night." (copula was omitted)

"You guys better get on the train." (main verb has been omitted)

"Hitting the tree." (subject omitted)

2. The speech sample must be a block of consecutive utterances. The clinician should try to include the child's "best" performance in the sample and should scan his/her transcript to find the section where a block of consecutive utterances would include his/her "best" utterances.

3. All utterances in a language sample must be different. No repetitions of sentences are to be included.

4. Unintelligible utterances should be excluded from the corpus. If the clinician is in doubt about any part of an utterance that affects the grammatical structure, then the utterance should be discarded.

5. Echoed utteranes should be excluded from the corpus. The clinician is interested in the child's self-formulated grammatical structures. Sentences which are first formulated by the clinician and then echoed by the child must be discarded. 